\title{
The effect of thiamin tetrahydrofurfuryl disulfide on behavior of juvenile DBA/2J mice
}

\author{
Judith I. Hills ${ }^{\text {a, }}$, Mari S. Golub ${ }^{\text {b }}$, Lucien Bettendorff ${ }^{c}$, Carl L. Keen ${ }^{\text {a,* }}$ \\ a Department of Nutrition, One Shields Ave., University of CA, Davis, CA 95616, USA \\ b BMB/CNPRC, University of CA, Davis, CA 95616, USA \\ c GIGA-Neurosciences, University of Liège, B-4000 Liège Belgium
}

\section{A R T I C L E I N F O}

\section{Article history:}

Received 11 February 2010

Received in revised form 26 May 2011

Accepted 19 July 2011

Available online $\mathrm{xxxx}$

\section{Keywords:}

Thiamin

Behavior

Learning

Social

Activity

Acoustic startle prepulse inhibition

\begin{abstract}
A B S T R A C T
Due to genetic defects or illness some individuals require higher amounts of thiamin than are typically 23 provided by the diet. Lipid-soluble thiamin precursors can achieve high blood levels of thiamin and result in 24 increased concentrations in the central nervous system. High intakes of thiamin have been reported as 25 beneficial in children with autism and attention deficit/hyperactivity disorder. The current study examined 26 the effect of thiamin tetrahydrofurfuryl disulfide (TTFD), a lipophilic precursor, on behavior in the juvenile 27 male DBA/2J mouse. Mice given by oral gavage deionized water or deionized water providing $100 \mathrm{mg}$ or 28 $340 \mathrm{mg}$ TTFD/kg body weight daily for 17 days, starting at postnatal day 18 , were tested for effects on operant 29 learning, social interaction, general activity level, and prepulse inhibition of acoustic startle, as well as effects 30 on growth and select organ weights. Results indicate lower activity and altered social interaction at both 31 treatment levels and decreased acoustic startle at the $100 \mathrm{mg} / \mathrm{kg}$ level. Compared to controls, percent weight 32 gain was lower in the TTFD-treatment groups, but percent body length increase was not affected by TTFD 33 treatment. TTFD treatment did not influence percent organ weights as percentage of body weights. TTFD 34 treatment resulted in increased whole brain thiamin concentrations. These results support the concept that 35 lipophilic thiamin precursors provided during early development can affect a number of behavioral 36 parameters. In clinical trials with children with behavior disorders, attention should be given to preventing 37 possible adverse gastrointestinal irritant effects associated with TTFD therapy.
\end{abstract}

(c) 2011 Published by Elsevier Inc. 39

\section{Introduction}

Thiamin, vitamin B-1, has several known functions in the body that have the potential to affect brain activity and behavior. As thiamin diphosphate (ThDP) it serves as a cofactor for enzymes involved in energy metabolism and formation of essential body constituents (McCormick, 2000) as well as the degradation of 3-methyl branched

Abbreviations: ASPPI, acoustic startle prepulse inhibition; AThTP, adenosine thiamin triphosphate; AThDP, adenosine thiamin diphosphate; b.i.d., twice daily; $\mathrm{BxD}$, recombinant cross of C57Bl/6 with DBA/2 mice; HACTV, horizontal locomotor activity beam breaks; $\mathrm{dB}$, decibels; HFHL, high frequency hearing loss; In, natural log; LnSt, starting body length at postnatal day 18; LRM, localized, non-ambulatory, repetitive movement beam breaks; LSMeans, least squares means; $\mathrm{mAChR}$, muscarinic acetylcholine receptor; MBR, mean baseline response; MSR, mean startle response; nAChR, nicotinic acetylcholine receptor; PctCtr, percent of time in arena center; PctLnChg, percent length change since postnatal day 18; PctWtChg, percent weight change since postnatal day 18; PND, postnatal day; q.i.d., 4 times daily; q.i.d., four times daily; RT, resting time; sqrt, square root; T0, 0 mg thiamin tetrahydrofurfuryl disulfide/kg body wt; T100, $100 \mathrm{mg}$ thiamin tetrahydrofurfuryl disulfide/ $\mathrm{kg}$ body wt; T340, $340 \mathrm{mg}$ thiamin tetrahydrofurfuryl disulfide/ $\mathrm{kg}$ body wt: ThDP, thiamin diphosphate; ThMP, thiamin monophosphate; ThTP, thiamin triphosphate; TTFD, thiamin tetrahydrofurfuryl disulfide; Tx, TTFD treatment; VACTV, vertical (rearing) activity beam breaks; WtCur, current body weight; WtSt, starting weight at postnatal day 18 .

* Corresponding author. Tel.: +1 530752 6331; fax: +1 5307528966.

E-mail addresses: judyhills@gmail.com (J.I. Hills), msgolub@ucdavis.edu (M.S. Golub), l.bettendorff@ulg.ac.be (L. Bettendorff), clkeen@ucdavis.edu (C.L. Keen).

1 Permanent address: 43677 Montgomery Ave., Davis, CA 95618, USA. chain fatty acids and 2-hydroxy straight chain fatty acids (Casteels et al., 50 2007). Thiamin triphosphate (ThTP) activates $\mathrm{Cl}^{-}$uptake through maxi 51 chloride channels in excised patches of neuroblastoma cells, is involved 52 in nicotinic receptor clustering at the neuromuscular junction, and has 53 been hypothesized to play a role in brain cell signaling and protection 54 against mitochondrial oxidative stress (reviewed by Bettendorff and 55 Wins, 2009). Cell signaling functions have also been proposed for 56 adenosine thiamin triphosphate (AThTP) and adenosine thiamin 57 diphosphate (AThDP) (Frédérich et al., 2009). Other reported or 58 hypothesized functions include regulation of enzyme expression (e.g., 59 (Pekovich et al., 1998a)); alteration of neuronal membrane ion channels 60 that result in prolonged depolarization responses (Houzen and Kanno, 61 1998; Tallaksen and Tauboll, 2000); maintenance of nerve membrane 62 potentials (Itokawa, 1996); alteration of neurotransmitter release 63 (Yamashita et al., 1993) or uptake (Thomson and Marshall, 2006); 64 and antioxidant activity of unphosphorylated thiamin (reviewed by 65 (Gibson and Blass, 2007)).

The signs of thiamin deficiency are protean and manifest differently 67 depending on an individual's age, dietary deficiencies and relative 68 amounts of dietary carbohydrate, disease status, and genetic makeup 69 (Inouye and Katsura, 1965). Cells differ in their ability to uptake thiamin, 70 the amounts that are needed, and regulation of the different forms of 71 thiamin and their compartmentalization (Bettendorff, 1995; Pekovich 72 et al., 1998b). Specialized transporters limit the rate of thiamin uptake 73

0892-0362/\$ - see front matter @ 2011 Published by Elsevier Inc. doi:10.1016/j.ntt.2011.07.006 
74 (reviewed by (Bettendorff and Wins, 2009)); therefore, conditions affecting these transporters can influence thiamin requirements. Thus, in disease states that result in defects of upstream factors, such as enzymes or other proteins that interact with thiamin, a means of bypassing thiamin transport can be of value. Thiamin tetrahydrofurfuryl disulfide (TTFD) can be taken orally and absorbed without need for passage through thiamin transporters (Mitoma, 1973; Suzuoki et al., 1968). TTFD has been used clinically in Japan and the U.S. (Lonsdale, 2006), and is generally considered safe (Baker and Frank, 1976; Lonsdale, 1987a; Mizutani et al., 1971). The oral LD50 in mice is $2200 \mathrm{mg} / \mathrm{kg}$ (Anon, 1982).

Thiamin or TTFD has shown promise in the treatment of two neurological disorders in children. A pilot human study (Lonsdale et al., 2002) investigating treatment of young autistic children with $50 \mathrm{mg}$ b.i.d. by rectal suppository suggested positive results with respect to improvements in behavior, speech, and sleep. A beneficial effect of highdose thiamin was also reported in children with hyperkinesis (Brenner, 1982) where 8 of 100 children responded favorably to $100 \mathrm{mg}$ q.i.d.; 4 of the children required supplementation long term, a finding that suggested a genetic basis to their high thiamin requirement. Researchers (Lonsdale, 1987a, 1982b, 1990, 2006) have reported other multifaceted behavioral and somatic disorders in children that have responded to thiamin or lipophilic thiamin precursor administration. In adults, lipophilic forms of thiamin have been used to treat psychobehavioral inhibition and asthenia, enhance memory in elderly patients, and improve cognitive function and reduce anxiety in university students with severe psychosomatic fatigue (reviewed by (Van Reeth, 1999)), as well as a number of other disorders which will be reviewed below in Section 4.4.

This present study was undertaken to focus specifically on behavioral effects of pharmacologic doses of thiamin provided via oral TTFD. The test animal was the juvenile male DBA/2J mouse, an inbred strain that has been widely studied and characterized. The possibility that this mouse may have a defect in thiamin utilization has been advanced, though not substantiated (Eudy et al., 2000; Lonsdale, 1982a). This mouse experiences rapid age-related hearing loss (Johnson et al., 2008). TTFD treatment reportedly extends juvenile DBA/2J susceptibility to audiogenic seizures (Lonsdale, 1982a), a finding that could indicate a change in the advance of their hearing loss. The present study used juvenile mice in order to simulate effects of supplementation in young children with behavioral disorders.

To assess behavioral effects of TTFD, we developed a rapid, sequential test battery including operant learning, social dyadic interaction, monitoring of activity levels over a 24-h period, and prepulse inhibition of acoustic startle. Low response rates in the juvenile mice during the evaluation of operant learning and technical difficulties with the apparatus minimized the ability to draw conclusions from this assessment, thus these data are not presented.
All experimental and stimulus mice were caged with littermates 136 until postnatal day (PND) 21, at which time experimental mice were 137 individually caged, whereas stimulus mice were then paired with a 138 non-littermate, with change to a different non-littermate each day 139 until social dyadic testing was completed. This re-pairing of stimulus 140 mice prevented frequent rearing and jumping (escape) behavior seen 141 in preliminary studies when stimulus mice were continuously caged 142 with littermates.

Mice were housed under temperature $\left(20-22^{\circ} \mathrm{C}\right.$ ) and light- 144 controlled (reverse phase, lights on 21:15-09:15) conditions and 145 fed a complete, purified egg white protein based diet (Dyets modified 146 AIN-93G) and deionized water ad lib throughout the study period, 147 except as follows: for experimental mice, food was restricted 4-h prior 148 to the 2-h training session for operant learning and the 2-h operant 149 learning test itself. As is common in nutritional studies, treatments for 150 experimental mice were initiated upon receipt of the mice. 151

From PND 18 to PND 34 experimental mice were given daily oral 152 gavage (at 09:00 for squad 1, at 11:30 for squad 2) with $5 \mu \mathrm{l} \mathrm{fluid/g} 153$ body weight. Gavage treatments were deionized water (control, T0, 154 $\mathrm{n}=24), 100 \mathrm{mg}$ TTFD $/ \mathrm{kg}$ body weight in deionized water $(\mathrm{T} 100,155$ $\mathrm{n}=23$ ), or $340 \mathrm{mg}$ TTFD $/ \mathrm{kg}$ body weight in deionized water (T340, 156 $\mathrm{n}=24$ ). These dosages correspond on a thiamin molar basis to 157 lipophilic forms of thiamin used in previous studies with mice 158 (Lonsdale, 1982a; Micheau et al., 1985). 159

With the exception of the 24-h activity test, the tests were 160 conducted approximately 3-h after gavage, during the first half of the 161 dark cycle, a time mice are naturally active. Mice were transported to 162 and from test locations in a dark, insulated container. 163

Mice used for tissue analysis were divided into the same three 164 treatment groups ( $n=5-6 /$ group), reared under similar conditions as 165 the mice used for the behavioral work (without behavior testing), 166 provided deionized water and a similar diet (Kwik-Uribe et al., 2000) 167 supplemented with additional thiamin to bring the thiamin content to 168 the same level (5 mg/kg diet) as provided to the experimental mice 169 and as meets the recommended intake level for mice (N.R.C.U.S.S.o.L.A, 170 1995). After 12 days of gavage treatment, the mice were euthanized by 171 $\mathrm{CO}_{2}$ inhalation and whole brain was removed for thiamin analysis. 172

\subsection{Study design}

The timeline for the behavioral study is given in Table 1.

\subsection{Growth and organ weights}

Experimental mice were weighed daily before gavage, and body 176 length (nose to rump) was determined at the start of the study and 177 before necropsy. Mice were observed at both the start and end of the 178 study to detect any changes in general activity, ambulation, posture, 179

Table 1

Timeline for study ${ }^{\mathrm{a}}$.

\begin{tabular}{|c|c|}
\hline Postnatal day & Animal care and testing \\
\hline 18 & $\begin{array}{l}\text { Receive mice. Weigh, measure length, observe, assign to squad } \\
\text { and treatment }\end{array}$ \\
\hline 21 & $\begin{array}{l}\text { Individually cage experimental mice. Pair cage stimulus mice } \\
\text { with non-littermate. }\end{array}$ \\
\hline $22-28$ & Re-pair stimulus mice \\
\hline 25 & Dipper training for operant test \\
\hline 26 & Operant test \\
\hline 27 & Social dyadic interaction, session 1 \\
\hline 28 & Social dyadic interaction, session 2 \\
\hline 29 & Test of 24-h activity, squad 1 \\
\hline 30 & Test of 24-h activity, squad 2 \\
\hline 32 & Prepulse inhibition of acoustic startle test \\
\hline 34 & Weigh, measure length, observe, necropsy for organ weights \\
\hline
\end{tabular}

$\mathrm{t} 1.1$ 1.2 1.4 .9 1.11 1.12 1.13 14

Please cite this article as: Hills JI, et al, The effect of thiamin tetrahydrofurfuryl disulfide on behavior of juvenile DBA/2J mice, Neurotoxicol Teratol (2011), doi:10.1016/j.ntt.2011.07.006 
appearance, or behavior. On PND 34, $3 \mathrm{~h}$ after gavage, mice were euthanized by $\mathrm{CO}_{2}$ inhalation, and the brain, testes, liver, spleen, kidneys, and heart were rapidly removed and weighed.

\subsection{Behavior tests}

\subsubsection{Social dyadic interaction test}

Mice proceeded to this test after completing the operant behavior test, which is not discussed due to procedural difficulties with that test (unpublished data). Social behaviors were studied by pairing each experimental mouse with a DBA/2J stimulus mouse (a mouse of the same age and sex that did not receive gavage treatment with TTFD or water) on two consecutive days. Experimental and stimulus mice were ranked and paired according to weight. Stimulus mice were used once on each of the consecutive test days and were paired with different experimental mice on the two days. Prior to starting the test, the stimulus mouse was marked with a black marker for identification then both mice were placed in separate Plexiglas holding chambers $\left(3.1 \mathrm{~cm}^{2}\right)$ identical to the test chamber and allowed to acclimate for $5 \mathrm{~min}$. Following acclimation, both mice were placed in the test chamber at the same time, and videotaped for 10 min under low illumination. The chambers were cleaned before testing each pair of mice.

An experienced observer, blinded to the experimental treatment, scored the number and duration of focal (experimental) mouse behaviors using Noldus Observer 5.0 software (Wageningen, the Netherlands) according to categories adapted from Terranova and Laviola (Terranova and Laviola, 2001). Behaviors were grouped into categories that reflected activity level and orientation of activity (toward the stimulus mouse vs. the environment) (Table 2).

\subsubsection{4-h activity monitoring}

Activity monitoring was conducted in an enclosed, automated 'open field' (Integra, Accuscan, Columbus, $\mathrm{OH}$ ) as previously described (Golub et al., 2004), over a $24 \mathrm{~h}$ period, with data collected in 3-min time bins. Each mouse was placed in the apparatus chamber $\left(36 \mathrm{~cm}^{2}\right.$, Plexiglass box) containing access to food and water approximately $13 / 4 \mathrm{~h}$ prior to the end of the light cycle (which was uniformly set for the same time for each cohort), after being weighed and receiving its gavage treatment. The first $30 \mathrm{~min}$ of activity in the arena (data collected and analyzed in ten 3-min time bins) was used to determine adaptation to a novel environment and assess emotionality. For the remainder of the 24-h period, 3-min time bins were synchronized with respect to day/night cycle by using the time stamp on each 3-min time bin. Four hundred fifty one synchronized 3-min time bins (1353 min total) exclusive of the adaptation period were obtained for each mouse and divided into 23 time bins, the first consisting of 33 minutes, and the remaining time bins consisting of $1 \mathrm{~h}$ each. Means of activities for each time bin were obtained for each mouse. Activity

Table 2

Social dyadic interaction: behavior groups used for ANCOVA.

\begin{tabular}{|c|c|}
\hline Behavioral group & Component behaviors \\
\hline $\begin{array}{l}\text { Social passive: includes mild-mannered } \\
\text { association with the stimulus mouse }\end{array}$ & $\begin{array}{l}\text { Social inactive, push past, cuddle, } \\
\text { social receptive, turn away }\end{array}$ \\
\hline $\begin{array}{l}\text { Social active: includes vigorous interaction } \\
\text { with the stimulus mouse }\end{array}$ & $\begin{array}{l}\text { Groom partner, push under, crawl } \\
\text { over/under, follow }\end{array}$ \\
\hline $\begin{array}{l}\text { Total active: includes both social active } \\
\text { behavior and other vigorous activity } \\
\text { directed toward the environment }\end{array}$ & $\begin{array}{l}\text { Groom partner, push under, crawl } \\
\text { over/under, follow, explore, jump }\end{array}$ \\
\hline $\begin{array}{l}\text { Other: includes behaviors that were less } \\
\text { active or of uncertain intent regarding } \\
\text { the stimulus mouse }\end{array}$ & $\begin{array}{l}\text { Approach, social sniff, groom self, } \\
\text { rear }\end{array}$ \\
\hline
\end{tabular}

Component behaviors were grouped into larger behavioral groups (i.e., social passive, social active, total active, other) that reflected activity level and orientation of activity (toward the stimulus mouse vs. the environment). Analyses were conduced on these behavior groups. rhythms were also summarized for 75 min (25 3-min time bins) 225 following the beginning of the dark cycle, the time of peak activity. 226

\subsubsection{Acoustic startle/prepulse inhibition (ASPPI)}

This procedure tests the degree to which presentation of a brief low 228 intensity sound (the prepulse) provided $30-500 \mathrm{~ms}$ prior to a sudden 229 intense startle-producing sound (the pulse) inhibits the resulting startle 230 reflex. The prepulse normally reduces the startle response and is an 231 operational measure of sensorimotor gating, a process by which an 232 animal filters out extraneous information and protects against sensory 233 overload for (review see (Swerdlow et al., 2008)). Deficits in sensory 234 prepulse inhibition (PPI) are studied with reference to several disorders, 235 including schizophrenia, panic disorder, bipolar disorder, obsessive 236 compulsive disorder, comorbid Tourette syndrome/attention deficit 237 hyperactivity disorder, and Huntington's disease (for review see 238 Swerdlow et al., 2008). In rodents the startle response itself is commonly 239 used to assess emotional reactivity and the effects of anti-anxiety drugs 240 (Bourin et al., 2007; Grillon, 2008; McCaughran et al., 2000). Species and 241 strains within species differ in their regulation of startle and PPI 242 (Swerdlow et al., 2008).

A commercial startle reflex system (SR-LAB, San Diego Instru- 244 ments, San Diego, CA), previously described (Berman et al., 2008), was 245 used. The mouse was allowed to acclimate in the dark chamber for 246 5 min before testing commenced. The 10-min test session consisted of 247 50 stimulus trials presented in a pseudo random manner, separated 248 by inter-trial intervals of 5 - to 20 -s ( 5 s steps). Testing was divided 249 into 10 blocks, each consisting of five trial combinations: (i) 120-dB, 250 $40 \mathrm{~ms}$ startle alone, (ii) $120-\mathrm{dB}, 40 \mathrm{~ms}$ startle preceded by $74-\mathrm{dB} 251$ prepulse, (iii) $120-\mathrm{dB}, 40 \mathrm{~ms}$ startle preceded by $82-\mathrm{dB}$ prepulse, (iv) 252 $120-\mathrm{dB}, 40 \mathrm{~ms}$ startle preceded $90-\mathrm{dB}$ prepulse, and (v) no stimulus 253 (background white noise only), as previously described (Berman et 254 al., 2008).

\subsection{Necropsy and tissue analysis for thiamin and thiamin phosphates}

Following euthanasia by $\mathrm{CO}_{2}$ inhalation, the whole brain (including 257 olfactory bulb and brainstem) was rapidly excised, immediately frozen 258 in liquid nitrogen, and stored at minus $80^{\circ} \mathrm{C}$ until extracted and 259 analyzed by HPLC according to published methods (Bettendorff et al., 260 1991). The remaining pellet was dissolved in $2 \mathrm{ml} 1 \mathrm{~N} \mathrm{NaOH}$ in a warm 261 water bath, then analyzed for protein content by the Bradford method 262 (Bradford, 1976) using fatty acid-free bovine serum albumin as the 263 protein standard.

\subsection{Chemicals}

265

Chemical sources were as follows: TTFD from Cardiovascular 266 Research, Ltd (Concord, CA, USA); thiamin, ThMP, ThDP, tricholoroacetic 267 acid (99+\%, ACS), and bovine serum albumin from Sigma Aldrich 268 (St. Louis, MO, USA). Diethyl ether and stabilizer-free tetrahydrofuran 269 were from Biosolve (Valkenswaard, The Netherlands). ThTP and AThTP 270 were prepared as previously described (Bettendorff et al., 2003 and 271 Frédérich et al., 2009, respectively). Purified water was obtained using a 272 Barnstead NANO-pure system (Van Nuys, CA).

\subsection{Statistical analysis}

Analysis of variance (ANOVA) or covariance (ANCOVA) was 275 conducted with SAS 9.2 for Windows (SAS Institute, Inc., Cary, NC) 276 using the Mixed Procedure with Tukey-Kramer post hoc comparisons. 277 Cohort was used as the random effect. For repeated measures over 278 time an auto regressive structure [AR(1)] was used. The group option 279 was included where appropriate to optimize model fit. Differences in 280 all analyses were considered significant at $P<0.05$. $P$ values have been 281 rounded to $0.05,0.01,0.005,0.001,0.0005$, or 0.0001 , as appropriate. 282 The results of analyses showing significance of TTFD effects are 283 
presented in tables, along with details of the analyses. Where interactions of treatment with covariates occurred, between-group significance of treatment was examined at the 25th, 50th, and 75th percentiles of the covariate.

Because mice grow rapidly during the juvenile period, weight was measured at several time points during treatment, and the gain in weight from the pretreatment baseline to necropsy (percent weight change) and growth in length from baseline to necropsy were used as growth endpoints. Organs as percent of body weight were determined for each mouse at necropsy.

Lower weight gain (represented as percent weight change in analyses) may be an indicator of generally delayed development that could be reflected in behavior. Because weight gain was found to differ between TTFD treatment groups at early stages of behavioral testing, further analyses were conducted for those behavioral endpoints which showed direct effects of both TTFD and weight gain. These analyses produced a measure of total effect of treatment, derived from path analysis, which takes into account how treatment directly affects behavior as well as how it indirectly affects behavior through its effect on weight gain. Comparison of direct and total effects (not shown) indicated that although some behavioral effects of TTFD occurred partially through effects on weight or weight gain, that component was much smaller than the direct effect.

For the social dyadic interaction test, the duration and number of episodes for each behavior group for the two sessions were analyzed by repeated measures ANCOVA, and ANCOVA was also performed on the mean of the two sessions for each behavior. Analysis of episode and duration data yielded similar results; only the duration data group comparisons are presented.

For the activity test adaptation period, data were analyzed by repeated measures ANCOVA across ten 3-min time samples. Repeated measures ANCOVA of variables over the 24-h period (time bins synchronized for the light/dark cycle, excluding the adaptation period) was conducted using each subject's means for 23 time bins described in Section 2.4.2. Spline graphs were used to examine the rhythm of several activity measurements during the light $\rightarrow$ dark transition period. Mean values of these variables for each of the twenty-five 3-min time samples following onset of the dark cycle were plotted using sm50 interpolation and analyzed with polynomial mixed models. When interactions of treatment $\times$ sample were significant and the model with those interactions showed better fit than the model without the interactions, treatment was considered to significantly affect the activity pattern.

For the acoustic startle prepulse inhibition test, means for baseline (i.e., no stimulus) response, startle response, and startle response following each prepulse level were obtained for each mouse. Acoustic startle prepulse inhibition (ASPPI) was calculated as ( 1 - (startlefollowing-prepulse/startle-without-prepulse) $)^{*} 100$ ). ANCOVA was performed on mean baseline response, mean startle response, and mean acoustic startle prepulse inhibition using both concurrent weight (a mechanical effect) and percent weight change (a developmental effect) as covariates. Since preliminary analyses indicated the mechanical effect of current weight showed greater effects than the developmental effect of percent weight change, only the results with the former covariate are presented. Due to a significant effect of treatment on current weight, path analyses were performed, and the total effects of treatment are presented in the table and figures for this test.

\section{Results}

\subsection{Growth and organ weights (Table 3)}

A between-group difference in percent weight change was significant by PND 26, the time of the operant test $\left(F_{2,10.4}=4.04\right.$, $\mathrm{P}=0.0503, \mathrm{~T} 340<\mathrm{T0}, \mathrm{P}<0.05$, a $28 \%$ decrease). At study end (PND 34), compared to T0 percent weight change of both T100 and T340 mice was lower (Fig. 1A), but growth in length did not differ between 347 treatment groups (Fig. 1B). Greater starting weight (at PND 18) and 348 greater starting length were associated with lower weight gain and 349 lower length gain, respectively. At the time of the acoustic startle 350 prepulse inhibition (ASPPI) test, compared to T0 current weight was 351 less in T100 $(\mathrm{P}<0.01)$ and T340 $(\mathrm{P}<0.05)$ mice. Current weight was 352 also significantly positively associated with starting weight. No 353 significant between-group differences were found in organ weights 354 (brain, liver, spleen, heart, kidneys, testes) when expressed as percent 355 of body weight (analysis data not shown) (Table 3).

\subsection{Behavior tests}

\subsubsection{Social dyadic interaction test}

Severe aggressive behavior occurred with two dyads (aggression 359 by a control mouse in one instance and by a T340 mouse in the other 360 instance), preventing observation of other normal behaviors. These 361 two dyads were removed from the analysis (Fig. 2).

Repeated measures ANCOVA of data from the two observation 363 sessions (Table 4) showed treatment effects for duration of behavior 364 in the categories Social Passive (T0 less than T340, $\mathrm{P}=0.01$ ), Social 365 Active (T0 greater than T100 and T340, $\mathrm{P}<0.01$ each), and Total Active 366 (T0 greater than T100 and T340, $\mathrm{P}<0.0005$ and $=0.0001$, respective- 367 ly) but not the Other behavior category. ANCOVA of the mean 368 activities from the two sessions also showed significant treatment 369 effects, and the direction of between-group differences was similar 370 (Table 4, Fig. 4). Mean episodes of social passive behavior were 371 significantly lower (13\%) in the second test session, indicating 372 adaptation to the test for that behavioral category (data not shown). 373
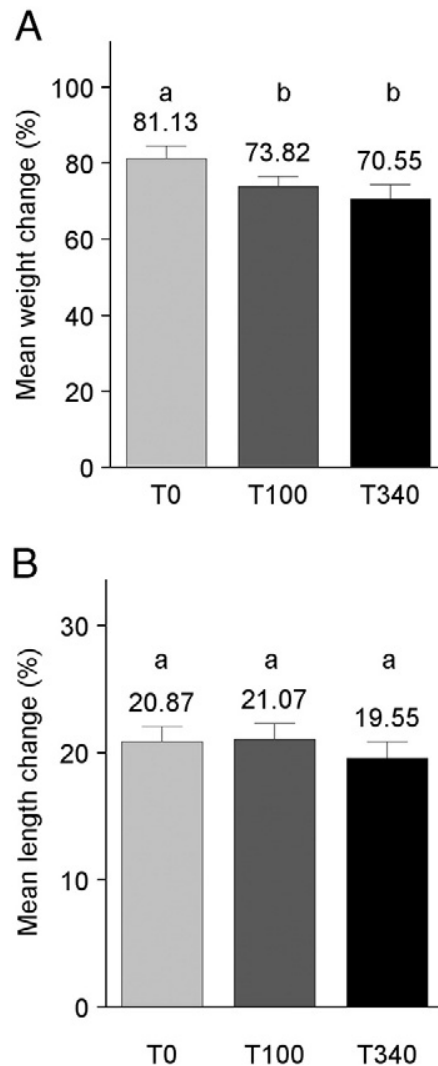

Fig. 1. Percent weight change gain (PctWtChg) and percent length change (PctLnChg) (Table 3). Changes in weight and length (nose to rump) between study start and study finish were computed for each mouse. (A) ANCOVA for PctWtChg showed T0 > T100 and T340, $\mathrm{P}<0.05$ each. (B) ANCOVA for PctLnChg showed no between-group differences. Between-group differences are indicated by a vs. b notation. Error bars represent S.E.M. T0 $=$ control $(n=19), T 100=100 \mathrm{mg}$ TTFD $/ \mathrm{kg}$ body weight $(\mathrm{n}=20), \mathrm{T} 340=340 \mathrm{mg}$ TTFD $/ \mathrm{kg}$ body weight $(\mathrm{n}=23)$. 
t3.1 Table 3

Statistical analysis results for growth ${ }^{\mathrm{a}}$.

\begin{tabular}{|c|c|c|c|}
\hline Transformed variable & $\begin{array}{l}\text { ANCOVA }^{\text {b }} \text { fixed } \\
\text { effects }\end{array}$ & \multicolumn{2}{|c|}{$\begin{array}{l}\mathrm{F} \text { test, } \operatorname{Pr}>\mathrm{F} \text { for treatment } \\
\text { and significant covariates }\end{array}$} \\
\hline $\begin{array}{l}\text { Ranked WtCur } \\
\text { (at ASPPI test) }\end{array}$ & $\mathrm{Tx} \mid \mathrm{WtSt}$ & $\begin{array}{l}\text { Tx } \\
\text { WtSt }\end{array}$ & $\begin{array}{l}\mathrm{F}_{2,66}=5.82, \mathrm{P}=0.0047 \\
\mathrm{~F}_{1,66}=84.78, \mathrm{P}<0.0001\end{array}$ \\
\hline $\begin{array}{l}\text { Squared PctWtChg } \\
\text { (at necropsy) }\end{array}$ & Tx|WtSt & $\begin{array}{l}\text { Tx } \\
\text { WtSt }\end{array}$ & $\begin{array}{l}\mathrm{F}_{2,67}=4.23, \mathrm{P}=0.0186 \\
\mathrm{~F}_{1,69}=14.67, \mathrm{P}=0.0003\end{array}$ \\
\hline $\begin{array}{l}\text { Ranked PctLnChg } \\
\text { (at necropsy) }\end{array}$ & Tx|LnSt|PctWtChg & $\begin{array}{l}\text { Tx } \\
\text { LnSt }\end{array}$ & $\begin{array}{l}\mathrm{F}_{2,60.9}=0.30, \mathrm{P}=0.7443 \\
\mathrm{~F}_{1,60.1}=30.49, \mathrm{P}<0.0001\end{array}$ \\
\hline
\end{tabular}

WtCur $=$ current weight, ASPPI test $=$ test for prepulse inhibition of acoustic startle, PctWtChg = percent change in weight from study start to necropsy, PctLnChg = percent change in body length from study start to necropsy, $\mathrm{Tx}=$ treatment, $\mathrm{WtSt}=$ body weight at study start $(\mathrm{PND} 18), \mathrm{LnSt}=$ body length (nose to rump) at study start (PND 18), rPctWtChg $=$ residual from regression of percent weight change on treatment.

t3.10 a $\mathrm{n}=19 \mathrm{T0}, 20 \mathrm{~T} 100,23 \mathrm{~T} 340$

b Vertical bars (I) indicate that significance of all indicated effects and their interactions was tested; however, as noted, the F test and significance levels are only listed for treatment (whether or not it reached significance) and other effects and t3.12 interactions that reached significance.

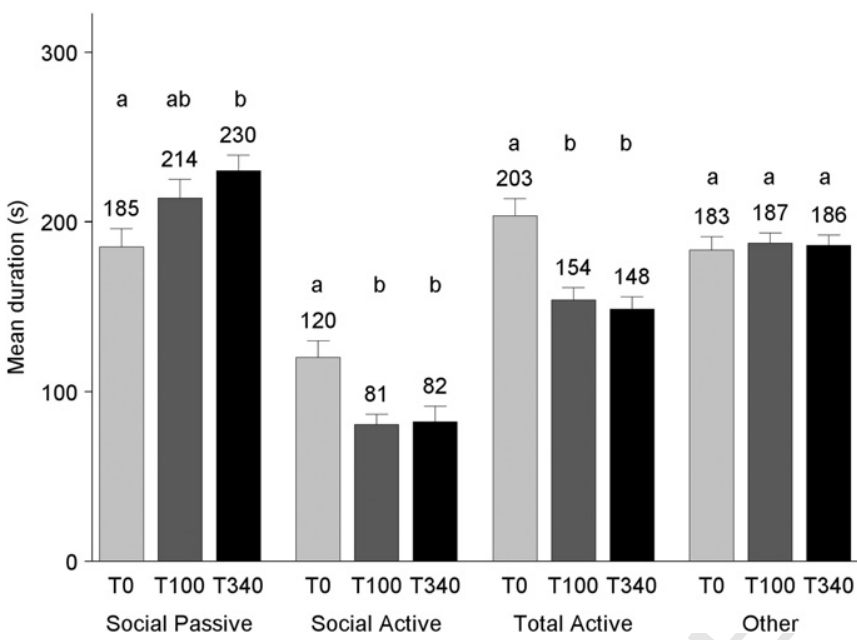

Fig. 2. Duration of activity in four behavior categories during social dyadic interaction (Table 4). Behaviors were quantified in two 10-min sessions for each mouse, and means of the two sessions are shown in the figure. ANCOVA of session means showed TTFD-treated groups differed from controls in three behavior categories: Social Passive, T340>T0 $(\mathrm{P}=0.01)$; Social Active, $\mathrm{T} 0>\mathrm{T} 100$ and $\mathrm{T} 340(\mathrm{P}<0.005$ and 0.01 , respectively $)$; and Total Active T0 $>$ T100 and T340 ( $<<0.0005$ each). Between-group differences are indicated by a vs. b notation. Error bars represent S.E.M. T0 $=$ control $(n=19), T 100=100 \mathrm{mg}$ TTFD $/ \mathrm{kg}$ body weight $(n=20)$, T340 $=340 \mathrm{mg}$ TTFD $/ \mathrm{kg}$ body weight $(n=23)$.

t4.1 Table 4

Statistical analysis results for duration of social dyadic behaviors ${ }^{\mathrm{a}}$

\begin{tabular}{|c|c|c|c|}
\hline \multirow{2}{*}{$\begin{array}{l}\text { Transformed variable } \\
\text { Repeated measures }\end{array}$} & \multirow[t]{2}{*}{$\begin{array}{l}\text { ANCOVA }^{\mathrm{b}} \\
\text { fixed effects }\end{array}$} & \multicolumn{2}{|c|}{$\begin{array}{l}\mathrm{F} \text { test, } \mathrm{Pr}>\mathrm{F} \text { for treatment } \\
\text { and significant covariates }\end{array}$} \\
\hline & & & \\
\hline Social passive behavior & Tx|Session & Tx & $\mathrm{F}_{2,55.4}=4.37 \mathrm{P}=0.0173$ \\
\hline sqrt Social active behavior & Tx|Session & Tx & $\mathrm{F}_{2,57.3}=7.00, \mathrm{P}=0.0019$ \\
\hline sqrt Total active behavior & Tx|Session & Tx & $\mathrm{F}_{2,59}=12.32, \mathrm{P}<0.0001$ \\
\hline Other behavior & Tx|Session & Tx & $\mathrm{F}_{2,59}=0.10, \mathrm{P}=0.9065$ \\
\hline \multicolumn{4}{|l|}{ Session means } \\
\hline Social passive behavior & $\mathrm{Tx}$ & $\mathrm{Tx}$ & $\mathrm{F}_{2,59}=4.50, \mathrm{P}=0.0150$ \\
\hline sqrt Social active behavior & Tx & Tx & $\mathrm{F}_{2,59}=7.20, \mathrm{P}=0.0016$ \\
\hline sqrt Total active behavior & Tx & Tx & $\mathrm{F}_{2,59}=12.40, \mathrm{P}<0.0001$ \\
\hline cubed other behavior & $\mathrm{Tx}$ & $\mathrm{Tx}$ & $\mathrm{F}_{2,59}=0.03, \mathrm{P}=0.9752$ \\
\hline
\end{tabular}

Analyses were conducted on behavior categories using (1) repeated measures on 2 test sessions and (2) the means of the 2 sessions.

t4.14 Tx $=$ treatment.

t4.16 a $\mathrm{n}=19 \mathrm{~T} 0,20 \mathrm{~T} 100,23 \mathrm{~T} 340$

b Vertical bars (I) indicate that significance of all indicated effects and their interactions was tested; however, as noted, the F test and significance levels are only listed for treatment (whether or not it reached significance). Other effects and t4.17 interactions did not reach significance.

\subsubsection{Activity monitoring}

374

During the first $30 \mathrm{~min}$ (adaptation) of the monitoring period, 375 TTFD-treated mice differed from control on three activity variables 376 (Table 5, Fig. 3). Compared to T0, percent time in the arena center was 377 reduced in both the T100 and T340 mice (Fig. 3B); localized repetitive 378 movement was significantly reduced for T340 mice (Fig. 3C); and 379 resting time was increased for both T100 and T340 mice (Fig. 3D). 380 Treatment did not significantly affect horizontal locomotor activity 381 (Fig. 3A). Habituation to the testing environment is indicated by 382 significant time (3-min sample) effects for each behavior. Greater 383 percent weight change (PctWtChg) was overall associated with 384 greater horizontal locomotor activity.

For the remainder of the 24-h period that was synchronized for the 386 light/dark cycle (Table 5, Fig. 4), significant treatment effects occurred 387

Table 5

Statistical analysis results for activity monitoring (adaptation and 24-h light cycle synchronized) a.

\begin{tabular}{|c|c|c|c|}
\hline $\begin{array}{l}\text { Transformed } \\
\text { variable }\end{array}$ & $\begin{array}{l}\text { ANCOVA }^{\mathrm{b}} \text { fixed } \\
\text { effects }\end{array}$ & \multicolumn{2}{|c|}{$\begin{array}{l}\mathrm{F} \text { test, } \mathrm{Pr}>\mathrm{F} \text { for treatment and } \\
\text { significant covariates }\end{array}$} \\
\hline \multicolumn{4}{|c|}{ Adaptation activity ${ }^{\mathrm{c}}$} \\
\hline \multirow[t]{3}{*}{ sqrt HACTV } & \multirow[t]{3}{*}{$\begin{array}{l}\text { Tx|3-min sample| } \\
\text { rPctWtChg }\end{array}$} & $\mathrm{Tx}$ & $\begin{array}{l}\mathrm{F}_{2,53.9}=1.54 \\
\mathrm{P}=0.2228\end{array}$ \\
\hline & & 3-min sample & $\begin{array}{l}\mathrm{F}_{9,318}=63.13 \\
\mathrm{P}<0.0001\end{array}$ \\
\hline & & rPctWtChg & $\begin{array}{l}\mathrm{F}_{1,73.8}=7.44 \\
\mathrm{P}=0.0080\end{array}$ \\
\hline \multirow[t]{2}{*}{ In PctCtr } & \multirow[t]{2}{*}{$\begin{array}{l}\text { Tx|3-min sample| } \\
\text { rPctWtChg }\end{array}$} & $\mathrm{Tx}$ & $\begin{array}{l}F_{2,52.6}=7.07 \\
P=0.0019\end{array}$ \\
\hline & & 3-min sample & $\begin{array}{l}\mathrm{F}_{9,105}=2.46 \\
\mathrm{P}=0.013\end{array}$ \\
\hline \multirow[t]{2}{*}{ sqrt LRM } & \multirow[t]{2}{*}{$\begin{array}{l}\text { Tx|3-min sample| } \\
\text { rPctWtChg }\end{array}$} & $\mathrm{Tx}$ & $\begin{array}{l}F_{2,97.3}=3.44 \\
P<0.0361\end{array}$ \\
\hline & & 3-min sample & $\begin{array}{l}\mathrm{F}_{9,462}=12.68 \\
\mathrm{P}<0.0001\end{array}$ \\
\hline \multirow[t]{2}{*}{ Cubed RT } & \multirow[t]{2}{*}{$\begin{array}{l}\text { Tx|3-min sample| } \\
\text { rPctWtChg }\end{array}$} & $\mathrm{Tx}$ & $\begin{array}{l}\mathrm{F}_{2,242}=146.1 \\
\mathrm{P}<0.0001\end{array}$ \\
\hline & & 3-min sample & $\begin{array}{l}\mathrm{F}_{2,541}=12.08 \\
\mathrm{P}<0.0001\end{array}$ \\
\hline \multicolumn{4}{|l|}{ 24-h activity ${ }^{c}$} \\
\hline \multirow[t]{2}{*}{ sqrt HACTV } & \multirow[t]{2}{*}{$\begin{array}{l}\text { Tx|Time bin| } \\
\text { rPctWtChg }\end{array}$} & Tx & $\begin{array}{l}F_{2,337}=3.35 \\
P=0.0363\end{array}$ \\
\hline & & Time bin & $\begin{array}{l}\mathrm{F}_{22,1212}=85.09 \\
\mathrm{P}<0.0001\end{array}$ \\
\hline \multirow[t]{3}{*}{$\begin{array}{l}\text { ranked } \\
\text { PctCtr }\end{array}$} & \multirow[t]{3}{*}{$\begin{array}{l}\text { Tx|Time bin| } \\
\text { rPctWtChg }\end{array}$} & $\mathrm{Tx}$ & $\begin{array}{l}\mathrm{F}_{2,101}=3.52 \\
\mathrm{P}=0.0332\end{array}$ \\
\hline & & Time bin & $\begin{array}{l}\mathrm{F}_{22,1183}=35.42 \\
\mathrm{P}<0.0001\end{array}$ \\
\hline & & Tx*rPctWtChg & $\begin{array}{l}F_{2,101}=3.11 \\
P=0.0491\end{array}$ \\
\hline \multirow[t]{3}{*}{ sqrt LRM } & \multirow[t]{3}{*}{$\begin{array}{l}\text { Tx|Time bin| } \\
\text { rPctWtChg }\end{array}$} & $\mathrm{Tx}$ & $\begin{array}{l}\mathrm{F}_{2,179}=5.90 \\
\mathrm{P}=0.0033\end{array}$ \\
\hline & & Time bin & $\begin{array}{l}\mathrm{F}_{22,1125}=68.83 \\
\mathrm{P}=0.0001\end{array}$ \\
\hline & & $\begin{array}{l}\text { Tx*Time bin* } \\
\text { rPctWtChg }\end{array}$ & $\begin{array}{l}F_{44,1072}=1.45 \\
P=0.0301\end{array}$ \\
\hline \multirow[t]{2}{*}{ ranked RT } & \multirow[t]{2}{*}{$\begin{array}{l}\text { Tx|Time bin| } \\
\text { rPctWtChg }\end{array}$} & $\mathrm{Tx}$ & $\begin{array}{l}\mathrm{F}_{2,868}=4.80 \\
\mathrm{P}=0.0084\end{array}$ \\
\hline & & Time bin & $\begin{array}{l}\mathrm{F}_{22,479}=231.78 \\
\mathrm{P}<0.0001\end{array}$ \\
\hline
\end{tabular}

HACTV = horizontal locomotor activity beam breaks, PctCtr = percent of time in the arena center, $\mathrm{LRM}=$ localized repetitive movement, $\mathrm{RT}=$ resting time, $\mathrm{Tx}=$ treatment, 3-min sample $=$ time bins in which data were collected for analysis during adaptation, rPctWtChg = residual from regression of percent weight change on treatment, Time bin $=$ composite time samples used for light cycle-synchronized 24-h analysis (see Section 2.4.2), ${ }^{*}=$ interaction between effects.

a $\mathrm{n}=20 \mathrm{~T} 0,21 \mathrm{~T} 100,22 \mathrm{~T} 340$

b Vertical bars (I) indicate that significance of all indicated effects and their interactions was tested; however, as noted, the F test and significance levels are only listed for treatment (whether or not it reached significance) and other effects and interactions that reached significance.

c Repeated measures analyses were conducted on behaviors during (1) the 30-min adaptation period and (2) the remainder of the 24-h period that was synchronized for onset of the dark cycle.

Please cite this article as: Hills JI, et al, The effect of thiamin tetrahydrofurfuryl disulfide on behavior of juvenile DBA/2J mice, Neurotoxicol Teratol (2011), doi:10.1016/j.ntt.2011.07.006 

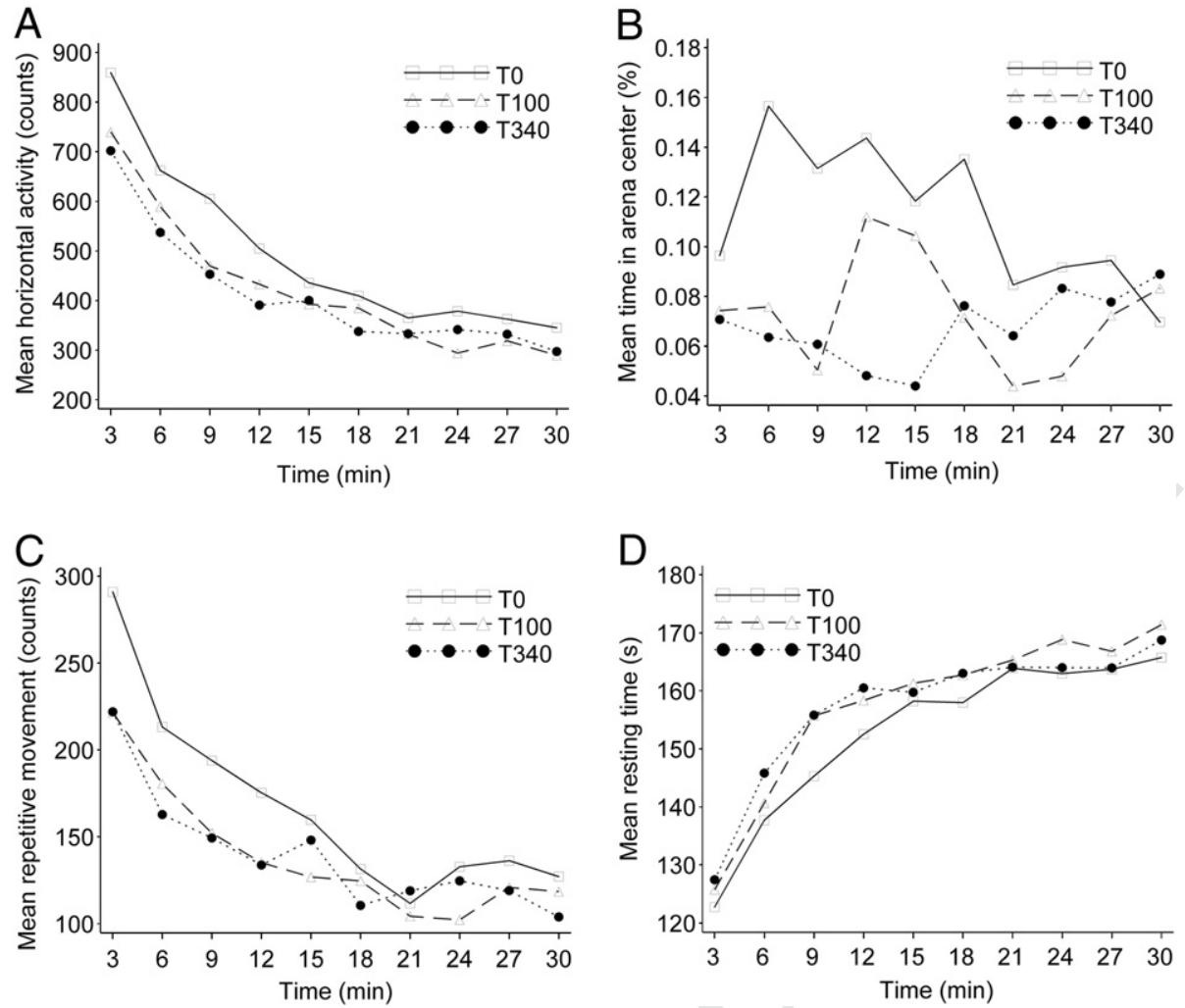

Fig. 3. Activity during open field adaptation (Table 5). (A-E) Plots depict mean levels of activities for each 3-min time segment during the first 30-min in the open field chamber. (A) Treatment did not significantly affect horizontal activity horizontal activity (HACTV). Significant treatment effects occurred for (B) percent time in arena center (PctCtr), with T0 $>$ T100 and T340 ( $<<0.05$ and $<0.01$, respectively); (C) localized repetitive movements (LRM), with T340 $<$ T0 (P $<0.05)$; and (D) resting time (RT), with T0 $<$ T100 and T340 $(\mathrm{P}<0.0005$ and $\mathrm{P}<0.0001$, respectively). Significant time effects occurred for $\mathrm{ABCDE}$, indicating habituation. T0 $=$ control $(\mathrm{n}=20), \mathrm{T} 100=100 \mathrm{mg}$ TTFD $/ \mathrm{kg}$ body weight $(\mathrm{n}=21)$, $\mathrm{T} 340=340 \mathrm{mg} \mathrm{TTFD} / \mathrm{kg}$ body weight $(\mathrm{n}=22)$.

for mean horizontal locomotor activity (Fig. 4A), with T0 greater than T100; for percent time in the arena center (Fig. 4B), with T100 greater than T0 at covariate means; for mean localized repetitive movement (Fig. 4C), with T0 greater than T100; and resting time (Fig. 4D), with T100 greater than T0. In the analysis of percent time in the arena center, the interaction of treatment with rPctWtChg was evidenced by significant between-group effects (T100 greater than T0) at the 25th $(P=0.001)$ and 50th $(P<0.05)$, but not the 75 th , percentiles of PctWtChg. Close examination of subset analyses and figures of localized repetitive movement data did not clarify the nature of the 3-way interaction (rPctWtChg*Treatment*Time bin*). Significant time bin effects occurred for all activity measurements (Table 6).

During the day $\rightarrow$ night transition period (Fig. 5A-D, analysis data not shown), significant treatment effects occurred for horizontal locomotor activity, localized repetitive movement, percent time in center, and resting time. The spline plot for resting time shows a more marked decrease and slower rebound for controls compared to TTFD groups, and plots for the other measurements show decreased response amplitude for both TTFD treatment groups and delayed peaks for T100 mice relative to control.

\subsubsection{Acoustic startle/prepulse inhibition (ASPPI) (Table 7)}

Compared to control (T0), mean baseline (no stimulus) response (MBR) was greater for T100 and T340 (Fig. 6A), and greater current body weight (WtCur) was significantly positively associated with MBR. The mean startle response of T100 was lower than that of T0. For the 82-dB prepulse, percent startle inhibition of T100 was lower than that of T0 and T340. The analysis was repeated using mice matched for magnitude of startle response to pulse alone ( $n=10$ per treatment group). These analyses showed no between-group differences in startle inhibition; the lower startle inhibition by the T100 group in the larger data set was due to their lower startle response. Treatment did not affect startle inhibition by the 74-dB or $90 \mathrm{~dB}$ prepulses. Although 419 a 3-way interaction (Treatment*rMBR ${ }^{*}$ rWtCur) occurred in the 74- $\mathrm{dB} 420$ analysis, no between-group differences were found at the 25th, 50th, 421 or75th percentile combinations of the covariates.

\subsection{Brain thiamin and thiamin phosphates}

TTFD treatment affected whole brain thiamin concentrations 424 (Table 8, Fig. 7). Significantly higher concentrations of thiamin 425 occurred in the T100 and T340 treatment groups compared to the 426 T0 group. No significant differences in brain tissue levels of the 427 phosphorylated thiamin derivatives ThDP or ThMP were observed, 428 and levels of ThTP and AThTP were too low for accurate quantification. 429

\section{Discussion}

\subsection{Growth and organ weights}

TTFD treatment resulted in a reduction in percent body weight 432 gain in both the T100 and T340 groups but there was no change in 433 percent body length gain. The effect on percent weight gain was 434 evident in the T340 group by the time of the first behavioral test. The 435 lower percent weight gain of TTFD-treated mice was not anticipated. 436 A previous study in which 14-16 week-old BALB/c mice were 437 administered $300 \mathrm{mg}$ of the lipophilic thiamin sulbutiamine daily by 438 oral intragastric intubation for $10 \mathrm{~d}$ did not report relative changes in 439 body weight (Micheau et al., 1985). Rodents given food supplemented 440 with another lipophilic thiamin precursor, thiamin propyl disulfide, 441 were reported to increase in body weight faster than those receiving 442 water soluble thiamin salts or no thiamin supplement (Shimazono 443 and Katsura, 1965). 
A

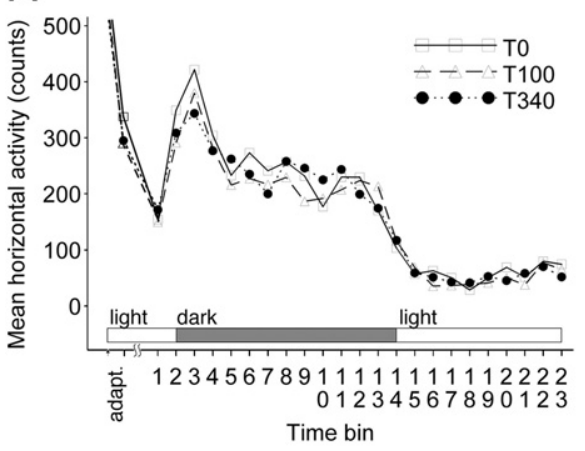

C

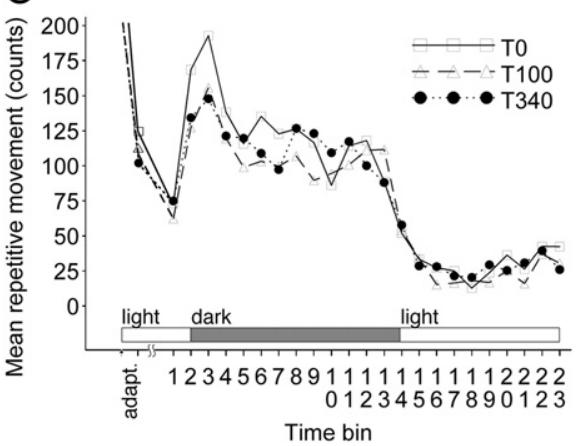

B

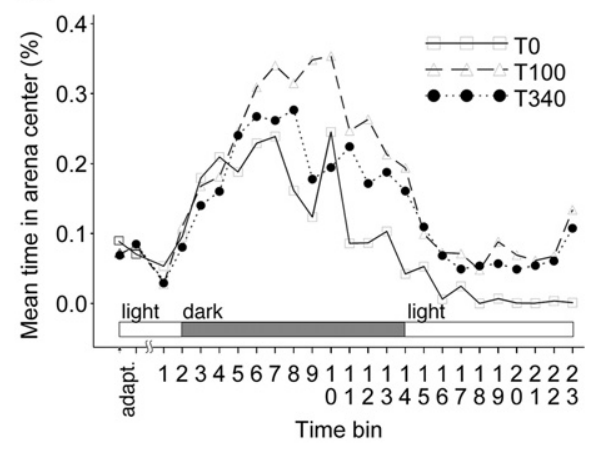

$\mathrm{D}$

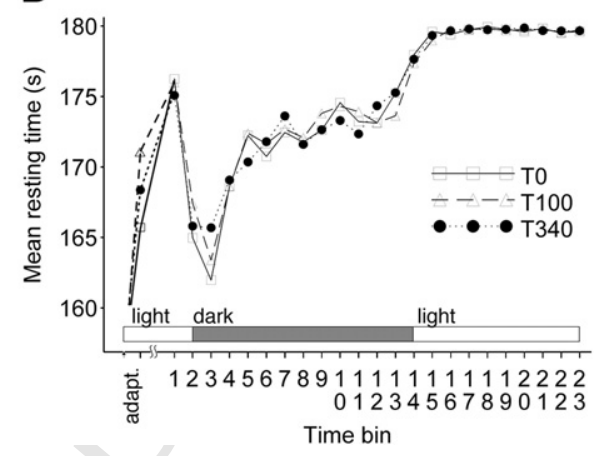

Fig. 4. 24-h open field activity, with time bins synchronized for the light/dark cycle (Table 6). The arrow indicates placement of mice into the chambers, which was immediately followed by the 30-min adaptation period presented in Fig. 3. The last adaptation measurement mean is indicated; the first adaptation measurement mean is indicated when the Y axis for the remaining light synchronized time period permitted. The discontinuity on the X axis represents the variable time elapsed to permit synchronization of the time bins following the adaptation period. The first time bin was 33 min long; the remaining time bins were $1 \mathrm{~h}$ long. Behavior means for each mouse were computed for each time bin and used for repeated measures ANCOVA. The figures represent treatment group means derived from individual means. Significant treatment effects occurred for (A) horizontal activity (HACTV) (T0 $>$ T100, P $<0.05$ ), (B) percent time in arena center (PctCtr) (T0 $<$ T100, P $<0.05$ at covariate means), (C) localized repetitive movement (LRM) (T0 $>$ T100, $<<0.005$ at covariate means), and (D) resting time (RT) (T0<T100, P $<0.01)$. A significant time bin effect occurred for each measurement $(\mathrm{P}<0.0001$ each). Interactions of covariates occurred for (B) and $(C)$, as discussed in Section 3.2.2. T0 $=$ control $(n=20), T 100=100 \mathrm{mg}$ TTFD $/ \mathrm{kg}$ body weight $(\mathrm{n}=21)$, T340 $=340 \mathrm{mg}$ TTFD $/ \mathrm{kg}$ body weight $(\mathrm{n}=22)$.

MBR $=$ mean baseline (no stimulus) response, $M S R=$ mean startle response to pulse alone, $\mathrm{dB}=$ decibels of sound, ASPPI = acoustic startle prepulse inhibition, $\mathrm{Tx}=$ treatment, $\mathrm{rWtCur}=$ residual from regression of current weight on treatment, $\mathrm{rMBR}=$ residual from regression of mean baseline response on treatment $\mid$ rWtCur, $*=$ interaction between effects.

t6.13 a $n=23$ T0, 24 T100, 23 T340

b Vertical bars $(\mid)$ indicate that significance of all indicated effects and their interactions was tested (however, as noted, the F test and significance levels are only listed for treatment (whether or not it reached significance) and other effects and t6.14 interactions that reached significance. indicated by the frequency with which their food cups required filling, 451 which suggests that decreased food intake, possibly due to an irritant 452 effect of TTFD gavage or decreased appetite, contributed to the lower 453 weight gain observed in these animals.

The dosages of TTFD used in this study were selected based on 455 previously published studies with lipophilic thiamin derivatives in 456 mice. However, one of those studies (Micheau et al., 1985) used older 457 mice, whose GI tracts may have been more robust, and a different 458 lipophilic thiamin (sulbutiamine) was used. In the second (Lonsdale 459 et al., 2002), TTFD was administered intraperitoneally. Should gavage 460 delivery of TTFD be causing irritation of the gastrointestinal tract, an 461 alternative method of delivery would need to be considered in future 462 studies. Lower dosages of TTFD could also be considered. TTFD 463 therapy in children (Lonsdale, 1987a, 2006, 2001, 2004; Lonsdale et 464 al., 1982, 2002) used doses lower than those used in the present study. 465 Attention to the route of administration or to buffering agents may be 466 needed in human studies.

Treatment resulted in a lower current body weight in both T100 468 and T340 mice at the time of the acoustic startle prepulse inhibition 469 (ASPPI) test. Because current weight can affect the mechanism of 470 startle detection, current weight was used as a covariate in the path 471 analysis model for components of that test.

\subsection{Behavior tests}

\subsubsection{Social dyadic interaction}

474

Control and TTFD-treated mice spent similar amounts of time with 475 the stimulus mouse, but the nature of their social interaction differed. 476 Compared to control, TTFD-treated mice showed more passive 477 (cuddling-type) interaction and less boisterous interaction with the 478 

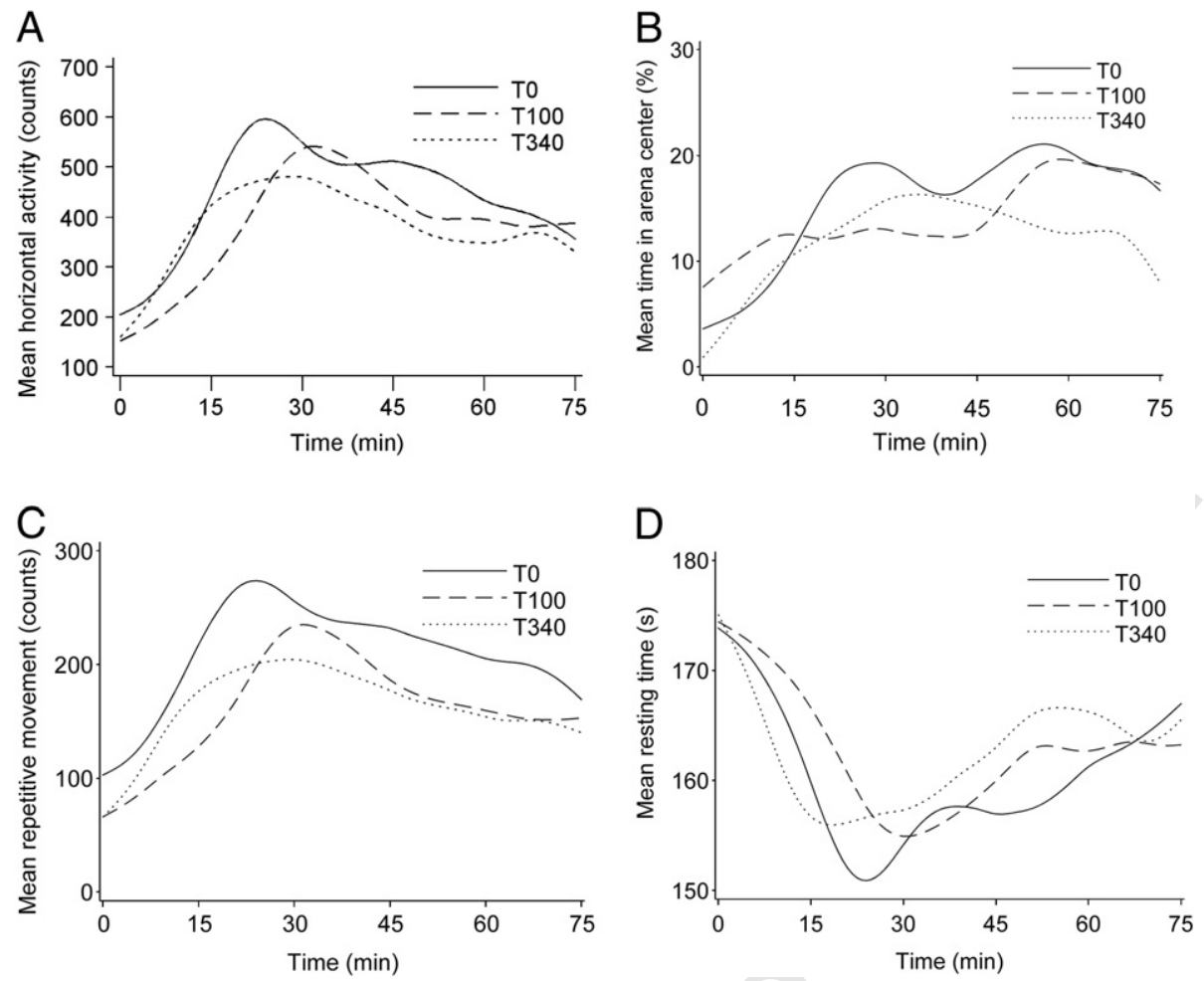

Fig. 5. Open field activity following onset of dark cycle. (A, B, C, D, E) Mean levels of activities were computed for each 3-min interval for 75 min following onset of the dark cycle and are plotted with sm50 interpolation. Polynomial mixed model analysis (explained in Section 2.7 ) indicated a significant treatment effect for each activity shown, with treatment $\times 3$-min sample significant $(\mathrm{P} \leq 0.05)$ at one or more levels of interaction in each case (data not shown). Active behaviors were decreased in amplitude for both $\mathrm{T} 100$ and $\mathrm{T} 340$, and were delayed in the T100 group. T0 $=$ control $(\mathrm{n}=20), \mathrm{T} 100=100 \mathrm{mg}$ TTFD $/ \mathrm{kg}$ body weight $(\mathrm{n}=21), \mathrm{T} 340=340 \mathrm{mg}$ TTFD $/ \mathrm{kg}$ body weight $(\mathrm{n}=22)$.

stimulus mouse. Results of the test suggest a dose-related lower total activity level in TTFD-treated mice.

Social proximity has previously been observed to be rewarding for the DBA/2J mouse (Moy et al., 2007; Panksepp and Lahvis, 2007). Further study is needed to determine whether the altered social activity observed in the TTFD-treated mice extends to animal models of childhood behavior disorders that are characterized by hyperactivity and disruptive interactions with peers. It has been suggested that nicotinic acetylcholine receptor (nAChR) function is involved in regulation of social behavior (Granon et al., 2003), and a cholinergic mechanism underlying thiamin effects has been proposed (see Section 4.2.2). Some childhood cases of hyperactivity have responded to high-dose thiamin (Brenner, 1982). Improved behavior has also been reported in autistic children treated with TTFD, but the nature of the improvements was not described (Lonsdale et al., 2002).

\subsubsection{4-h activity monitoring}

Open field testing yielded 3 main findings: (1) activity levels were generally lower in TTFD-treated mice than in controls, (2) different activities were altered in the adaptation period vs. the 24 -h period, and (3) during the light-dark transition period TTFD-treated groups showed a dose-related decrease in peak amplitudes of active behaviors and the T100 group showed a delay in active behaviors relative to controls.

During the adaptation period, for all treatment groups active behaviors generally decreased over time while resting time increased. Compared to control, the overall higher resting time for both TTFD groups, as well as lower localized repetitive movement for the T340 group, suggests decreased activity with TTFD treatment. Locomotor difficulties were not observed in TTFD-treated mice in the social dyadic test, suggesting innate motor deficits probably did not underlie decreased activity. The decrease in percent of time in the arena center for TTFD groups could signify increased anxiety or decreased risk taking, or it may have been a result of overall lower activity. The latter explanation may apply since center time was higher than T0 in the 512 T100 group during the 24-h period. Also, decreased acoustic startle 513 response in T100 compared to T0 mice in the ASPPI test may possibly 514 indicate decreased (rather than increased) anxiety (discussed below). 515 Further behavioral experiments could clarify whether thigmotaxis 516 (reduced center time in the open field) signified increased anxiety vs. 517 decreased risk taking during the adaptation period and whether there 518 were coordination problems that may not have been detected in the 519 current testing regimen (Curzon et al., 2009).

The 24-h data again indicate overall lower activity in TTFD-treated 52 mice compared to control, but in different components. Here control 522 mice showed greater horizontal activity than T100 mice (vs. no 523 between-group differences during adaptation); control mice showed 524 greater localized repetitive movement than only T100 (vs. T0 greater 525 than T340 during adaptation); and the average resting time for 526 controls was less than that of the T100 group (vs. T0 less than both 527 T100 and T340 during adaptation). Percent time in the arena center 528 was increased for T100 mice compared to controls (indicating 529 adaptation to that area with longer exposure), a result contrasting 530 to that found in the adaptation period where time in center was 531 greater for controls than for the T100 and T340 groups. Thus, the 532 dosage of TTFD resulted in differing effects on activity during each 533 activity period (adaptation and 24-h), and effects were not always 534 dose related.

The mechanism(s) underlying TTFD's effects on activity are 536 unknown, but several lines of evidence suggest that altered 537 cholinergic function could play a role. Previous experimental animal 538 and human studies have proposed that stimulation of cholinergic 539 function by TTFD could underlie its effect on brain function (Lonsdale, 540 1987a, 1987b, 1982a; Micheau et al., 1985; Mimori et al., 1996). In 541 normal human volunteers high-dose thiamin has been reported to 542 counteract hippocampal behavioral deficits induced by the non- 543 selective mAChR antagonist scopolamine (Meador et al., 1993). A 544 number of behavioral deficits seen in thiamin-deficient rodents are 545 
A

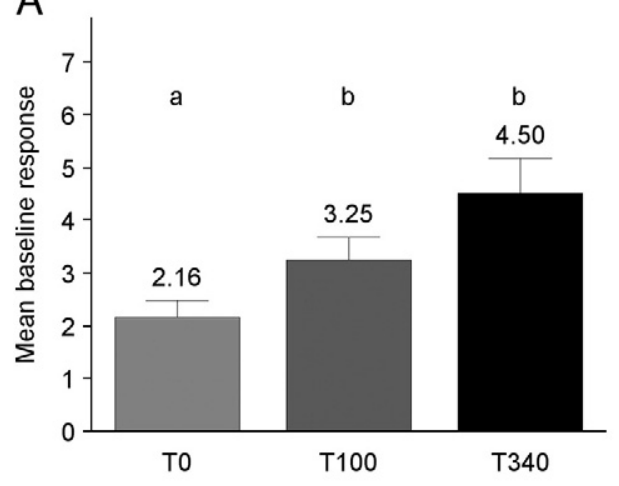

B

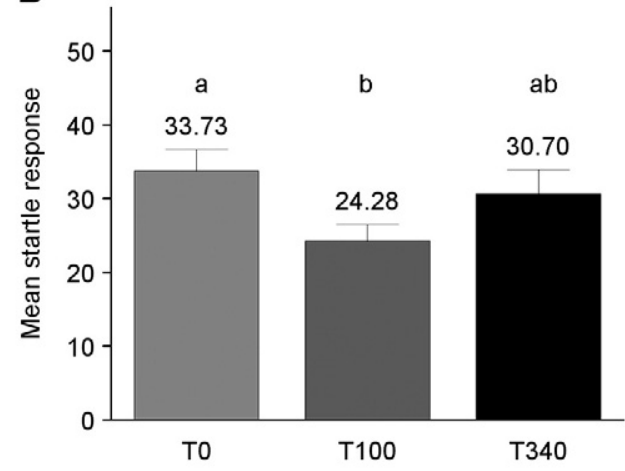

C

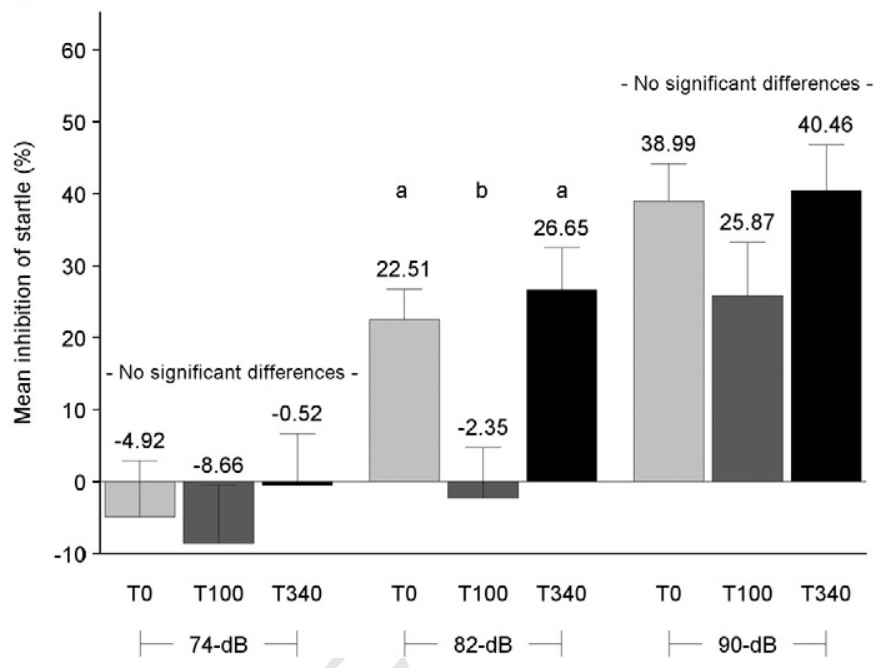

Fig. 6. Acoustic startle/prepulse inhibition (Table 7). Behavior means for each mouse were computed for each measurement and used for ANCOVA. The figures represent treatment group means derived from individual means. Significant treatment effects occurred for (A) mean baseline (no stimulus) response (MBR) with only background noise in the acoustic startle apparatus ( $\mathrm{T} 0<\mathrm{T} 100$ and $\mathrm{T} 340, \mathrm{P}<0.05$ and $\mathrm{P}<0.0005$, respectively); (B) mean startle response to pulse alone (MSR) (T100 $<\mathrm{T} 0$, $\mathrm{P}<0.05$ ); and $(\mathrm{C})$ startle inhibition by the 82 -dB prepulse (ASPPI) (T100 < T0 and T340, P $<0.01$ each). For the 74-dB and 90-dB prepulses, no significant treatment effect occurred. Between-group differences are indicated by a vs. b notation. Error bars represent S.E.M. T0 = control $(\mathrm{n}=23), \mathrm{T} 100=100 \mathrm{mg}$ TTFD $/ \mathrm{kg}$ body weight $(\mathrm{n}=23), \mathrm{T} 340=340 \mathrm{mg}$ TTFD $/ \mathrm{kg}$ body weight $(\mathrm{n}=23)$.

Statistical analysis results for HPLC analysis of whole brain content of thiamin and

thiamin phosphate (per mg protein) ${ }^{\mathrm{a}}$.

remediated by pro-cholinergic agents (Nakagawasai et al., 2001, 2000, $2007,2004)$. Thiamin can affect acetylcholine levels by (1) increasing levels of acetylcholine precursors via its cofactor roles in the pyruvate dehydrogenase complex (acetyl Co-A production) and transketolase (NADPH/antioxidant protective effect) (Gibson and Blass, 2007; Gloire et al., 2006; Jones, 2000; McGrane, 2000; Salminen and Kaarniranta, 2010; Sheline and Wei, 2006) and increasing the rate of neuronal high affinity uptake of choline (Micheau et al., 1985), and (2) preventing (via antioxidant protective effects) reduction of nerve growth factor induced transcription of choline acetyltransferase, the enzyme responsible for synthesis of acetylcholine (Toliver-Kinsky et al., 2000). Thiamin may differentially affect acetylcholine receptors; for example, thiochrome, an oxidation product and metabolite of thiamin, enhances the binding and actions of acetylcholine at muscarinic M4 relative to other muscarinic receptors (Lazareno et al., 2004).

\begin{tabular}{lll}
\hline Transformed variable & ANOVA fixed effect & $\mathrm{F}$ test, $\mathrm{Pr}>\mathrm{F}$ for treatment \\
\hline 1/Thiamin & $\mathrm{Tx}$ & $\mathrm{F}_{2,5.62}=27.05, \mathrm{P}=0.0013$ \\
ranked ThMP & $\mathrm{Tx}$ & $\mathrm{F}_{2,13}=0.48, \mathrm{P}=0.6317$ \\
1/cubed ThDP & $\mathrm{Tx}$ & $\mathrm{F}_{2,10}=0.85, \mathrm{P}=0.1383$ \\
\hline
\end{tabular}

$\mathrm{ThMP}=$ thiamin monophosphate, $\mathrm{ThDP}=$ thiamin diphosphate

${ }^{\mathrm{a}} \mathrm{n}=5 \mathrm{~T} 0,5 \mathrm{~T} 100,6 \mathrm{~T} 340$

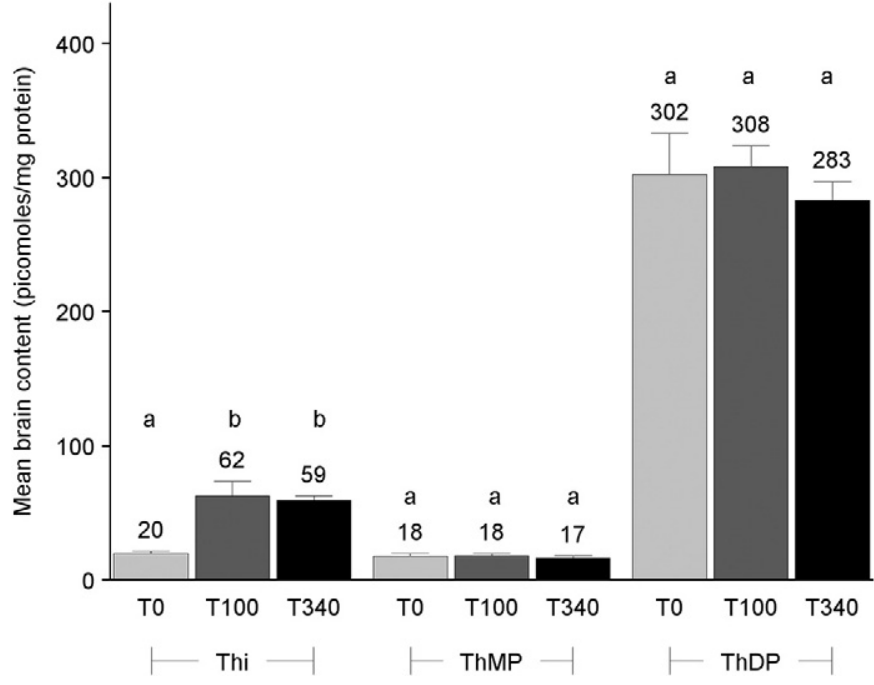

Fig. 7. Effect of treatment on the thiamin and thiamin phosphate content of whole mouse brain (Table 8 ). Tissue analysis showed between-group differences in the level of thiamin (Thi) $(\mathrm{T} 0<\mathrm{T} 100, \mathrm{P}<0.01 ; \mathrm{T} 0<\mathrm{T} 340, \mathrm{P}<0.001)$, but no between-group differences in levels of thiamin monophosphate (ThMP) or thiamin diphosphate (ThDP). Levels of thiamin triphosphate (ThTP) and adenosine thiamin triphosphate (AThTP) were too low to quantify accurately. Between-group differences are indicated by a vs. b notation. Error bars represent S.E.M. T0 $=$ control $(n=5), T 100=100 \mathrm{mg}$ TTFD $/ \mathrm{kg}$ body weight $(\mathrm{n}=23)$, T340 $=340 \mathrm{mg}$ TTFD $/ \mathrm{kg}$ body weight $(\mathrm{n}=6)$. 
Thiamin-related cholinergic enhancement may also be involved in regulation of circadian rhythm for reviews see (Datta, 2010; Rosenwasser, 2009; Turner et al., 2010), which could explain differences observed here during the light/dark transition. Subclinical dietary thiamin deficiency altered circadian rhythm in 6 week-old C57BL/6J mice (Bennett and Schwartz, 1999). Studies using other species have shown circadian activity effects of the lipophilic thiamin precursor sulbutiamine (Van Reeth, 1999). Limited human reports suggest effects of thiamin deficiency (Wilkinson et al., 1997) and thiamin augmentation via TTFD (Lonsdale et al., 2002) on sleep.

Further study is needed to elucidate the mechanism of the effect of TTFD on activity, sleep, and body rhythms and to determine if lipophilic thiamin precursors might benefit disorders of these functions in humans.

\subsubsection{Acoustic startle/prepulse inhibition (ASPPI)}

Although the DBA/2J mouse suffers juvenile-onset high frequency hearing loss (HFHL), previous tests demonstrated that the acoustic startle response is independent of HFHL in juvenile mice when the prepulse is broad-band white noise rather than pure tones (McCaughran et al., 1999). Our test protocol used broad-band noise in 32-d old mice.

Our ASPPI study yielded 4 main findings regarding TTFD effects: (1) TTFD produced a dose-related increase in mean baseline response (the no stimulus response during only broad-band background noise); (2) the response to the startle pulse alone was lower for T100 compared to T0 mice; (3) prepulse inhibition with the $82 \mathrm{~dB}$ prepulse was reduced for T100 compared to both T0 and T340 mice; and (4) when mice were matched for startle response, no change in 82-dB prepulse inhibition was observed.

Mean baseline (no stimulus) response increased with increasing current weight over the entire group of mice and also within each treatment group. Yet, despite their lower mean body weights, the T100 and T340 groups showed higher mean baseline response than controls, findings that suggest the increase in mean baseline response was not due primarily to the TTFD effect on weight. A rising baseline response in adult DBA/2 mice has been reported in response to high doses of stimulants (Flood et al., 2010) which was attributed to hyperactivity, such as increased turning behavior in the test cylinders, or finer stereotypic movements. An increased general activity in the startle chamber has also been noted in nicotine withdrawn DBA/2 mice (Semenova et al., 2003) which was suggested to reflect increased body tremor or agitation. The accentuated response in the confined environment by TTFD-treated mice contrasted with their decreased activity in the open field test and the social dyadic interaction test. A confined, isolated environment, such as the restraint cylinder used for acoustic startle testing, may solicit unique behaviors. Observation of control and TTFD-treated mice in tightly restrained containers would shed light on what behaviors are involved and whether T100 and T340 mice demonstrate less anxiety-induced freezing behavior.

T100, but not T340, mice showed decreased startle response compared to T0 mice, a finding that suggests activation of different neurotransmitter pathways depending on dosage. Pre-clinical thiamin deficiency in rodents has been shown to increase the startle response to electric shock and was correlated with reduced activity of erythrocyte transketolase, an enzyme for which thiamin diphosphate is a cofactor (Peskin et al., 1967). Increased startle response was attributed to neurological hyperexcitability and was thought to correlate with reported observations of increased spontaneous activity in preclinically thiamin-deficient rats. We know of no previous reports of supranormal thiamin intake decreasing auditory startle or startle due to other sensory input, however. In rodents the startle response is commonly used to assess emotional reactivity and the effects of anti-anxiety drugs (Bourin et al., 2007; Grillon, 2008; McCaughran et al., 2000). How TTFD affects various neurotransmitter systems impinging on startle and whether decreased startle in T100 mice indicates an anxiolytic effect at that dosage merits further study.
Compared to several other mouse strains, the DBA/2 strain has 627 shown spontaneously low auditory PPI (McCaughran et al., 1997; 628 Paylor and Crawley, 1997) and has been proposed as a model for 629 testing drugs intended for psychiatric conditions that demonstrate PPI 630 deficits (Olivier et al., 2001). Our study showed no improvement in 631 PPI with TTFD treatment. TTFD doesn't appear to offer potential for 632 treatment of disorders with disrupted sensory gating if PPI facilitation 633 is used as the criterion.

\subsection{Whole brain analysis for thiamin and thiamin phosphates}

635

TTFD treatment markedly increased the level of thiamin in whole 636 brain, but had no significant effect on concentrations of ThMP or ThDP. 637 Levels of ThTP and AThTP are extremely low in mice compared to rats 638 (Frédérich et al., 2009), and improved methods of detection are 639 needed.

Two recent studies, one in rats (Nozaki et al., 2009) and the other 641 in mice (Pan et al., 2010), also showed elevated levels of thiamin, but 642 not ThMP or ThDP with TTFD treatment. Results (unpublished) in our 643 laboratory suggest that ThDP levels in brainstem (medulla, pons, 644 inferior colliculi) of DBA/2J mice may be marginally increased by TTFD 645 administered via drinking water. Necropsy of a larger number of mice 646 is needed to obtain pooled samples of various brain regions for 647 analysis. Turnover of coenzyme-bound ThDP is slow (Bettendorff et 648 al., 1994), but it is possible that higher intracellular thiamin could 649 increase flux through the rapid turnover pools of ThDP and ThTP 650 without increasing the ThDP level.

\subsection{Other considerations}

Through studies in humans, animals, and cell cultures, highly 653 absorbable thiamin precursors have been shown to have beneficial 654 effects via a variety of mechanisms: e.g., on complications of diabetes 655 mellitus (e.g., (Du et al., 2010; Hammes et al., 2003; Karachalias et al., 656 2010)), vascular endothelial dysfunction (Verma et al., 2010), cognitive 657 function (Bizot et al., 2005; Micheau et al., 1985; Mimori et al., 1996; Pan 658 et al., 2010), endotoxin induced uveitis and lipopolysaccharide-induced 659 cytotoxic effect (e.g., (Yadav et al., 2010)), other inflammatory conditions 660 (e.g., (Matsui et al., 1985)), toxicity due to heavy metals and various 661 chemicals (Fujiwara, 1965; Lonsdale et al., 2002; Reddy et al., 2010), 662 alcoholic and nutritional polyneuropathies and myopathies (Djoenaidi et 663 al., 1992; Woelk et al., 1998), dysautonomic symptoms (Lonsdale, 2009), 664 infant brainstem dysfunction and apnea (Lonsdale, 2001), postinfectious 665 asthenia (Shah, 2003), psychobehavioral inhibition occurring during 666 major depression (Loo et al., 2000), and various disorders possibly 667 associated with thiamin dependency that are expressed particularly 668 under conditions of physical or emotional stress (Lonsdale, 1987a, 2006). 669

Thiamin requirements are not only influenced by various disease 670 conditions, as mentioned above, but by individual differences in 671 thiamin utilization. While a few notable examples of genetic disorders 672 influencing thiamin requirements have been well-studied [e.g. Leigh 673 disease and West syndrome, thiamin responsive megaloblastic 674 anemia with diabetes and deafness, and neuropathy and bilateral 675 striatal necrosis with exacerbation during febrile illnesses (Ames et 676 al., 2002; Spiegel et al., 2009), others that produce more subtle 677 behavioral changes or susceptibility to disease may well be awaiting 678 discovery and may underlie case reports of beneficial effects of 679 pharmacologic use of thiamin or its lipophilic derivatives (Lonsdale, 680 2006). Low frequency missense alleles of many different enzymes that 681 result in impaired function are hypothesized to be common and may 682 be nutrient sensitive (Marini et al., 2008). Combinations of nutrients 683 may be required in cases where vitamin function is compromised 684 (Ames et al., 2002). Also, when a pharmacologic dose of a nutrient is 685 used, downstream shifts in metabolic pathways may require 686 adjustment in the dietary intake of other nutrients (Lonsdale, 687 1987a, 1990). 
Even without underlying disease conditions or metabolic abnormalities that may increase thiamin requirement, children in Western nations may be at risk of inadequate thiamin nutriture. Because of its role in oxidative metabolism, the requirement for thiamin is increased with higher carbohydrate intake. Whereas the normal rodent diet contains high levels of thiamin relative to rodent requirements, the typical human diet does not (Fleming et al., 2003). Body stores of thiamin are limited, and the requirement for thiamin in infancy and childhood is relatively high (I.o.M. (U.S.), 2002). Concern has been expressed that in Western cultures relative thiamin deficiency may occur due to diets high in calories from refined carbohydrates, and that treatment of resulting functional disorders with physiological doses of thiamin provided in multivitamin preparations may not be sufficient to address defective enzyme/cofactor bonding that results from prolonged poor dietary habits (Lonsdale, 2006).

Apart from human case studies, long-term effects of TTFD on a range of behaviors have not been systematically studied to our knowledge. Alterations in morphology and neurotransmission during development can have long-term behavioral effects, even when the initiating nutrient or pharmaceutical is discontinued (e.g., Stevens et al., 2008). Study of behavioral effects of TTFD at different life stages with follow-up to assess residual effects on behavior is needed.

\section{Conclusion}

Behavioral and growth effects of diet supplementation with a lipophilic thiamin precursor, TTFD, were studied in the juvenile male DBA/2J mouse. TTFD was administered by gavage $(100 \mathrm{mg} / \mathrm{kg}$ and $340 \mathrm{mg} / \mathrm{kg}$ body weight). Compared to control, dose-related reduction in weight gain occurred. Treatment did not affect gain in body length or organ weights as percent of body weight. A sequential battery of behavioral tests was conducted, and data were analyzed taking into account treatment effects on weight gain. TTFD-treated mice showed decreased locomotor activity in solitary open field testing and also when interacting with a conspecific. During social interaction TTFD-treated mice engaged in more passive (cuddling-type) as opposed to vigorous play-type behavior. Mice treated with the lower dosage of TTFD showed decreased startle response to loud noise. Both treatment groups showed a significant increase in whole brain levels of thiamin, but no change in levels of the phosphorylated derivatives ThMP and ThDP. Further work is needed to ascertain the mechanisms underlying behavioral effects and to determine the potential for beneficial effects in treating children with behavioral disorders.

\section{Conflict of interest statement}

The authors certify that there is no financial conflict of interest between any of the authors and any company or product that is part of this research.

\section{Acknowledgments}

This research was supported by a University of CA, Davis, M.I.N.D. Institute Pre-Doctoral Scholar Fellowship to Judith I. Hills. Lucien Bettendorff is Research Director at the F.R.S.-FNRS, Belgium. Behavior testing was conducted at the University of CA, Davis, Murine Behavior Assessment Laboratory under direction of M.S. Golub.

\section{References}

Drugs in Japan 6 (1982) 99.

I.o.M. (U.S.). P.o. Micronutrients., Dietary reference intakes for thiamin, rboflavin, niacin, vitamin B6, folate, vitamin B12, pantothenic acid, biotin, and choline. A report of the Standing Committee on the Scientific Evaluation of Dietary Reference Intakes and its Panel on Folate, Other B Vitamins, and Choline and Subcommittee on Upper Reference Levels of Nutrients. Food and Nutrition Board, Institute of Medicine, Editoin Edition. Washington, D.C: National Academy Press; 2002.
Ames BN, Elson-Schwab I, Silver EA. High-dose vitamin therapy stimulates variant 748 enzymes with decreased coenzyme binding affinity (increased $\mathrm{K}(\mathrm{m})$ ): relevance to 749 genetic disease and polymorphisms. Am J Clin Nutr 2002;75:616-58. 750

Baker $\mathrm{H}$, Frank $\mathrm{O}$. Absorption, utilization and clinical effectiveness of allithiamines compared 751 to water-soluble thiamines. J Nutr Sci Vitaminol (Tokyo) 1976;22(Suppl):63-8. 752 Bennett MR, Schwartz WJ. Altered circadian rhythmicity is an early sign of murine 753 dietary thiamine deficiency. J Neurol Sci 1999;163:6-10. 754

Berman RF, Pessah IN, Mouton PR, Mav D, Harry J. Low-level neonatal thimerosal 755 exposure: further evaluation of altered neurotoxic potential in SJL mice. Toxicol Sci 756 2008;101:294-309.

Bettendorff L. Thiamine homeostasis in neuroblastoma cells. Neurochem Int 1995;26: 758 295-302.

Bettendorff L, Nghiem HO, Wins P, Lakaye B. A general method for the chemical 760 synthesis of gamma-P-32-labeled or unlabeled nucleoside 5'-triphosphates and 761 thiamine triphosphate. Anal Biochem 2003;322:190-7.

Bettendorff L, Peeters M, Jouan C, Wins P. Schoffeniels E. Determination of thiamin and its 763 phosphate esters in cultured neurons and astrocytes using an ion-pair reversed-phase 764 high-performance liquid chromatographic method. Anal Biochem 1991;198:52-9. 765

Bettendorff L, Wins P. Thiamin diphosphate in biological chemistry: new aspects of 766 thiamin metabolism, especially triphosphate derivatives acting other than as 767 cofactors. FEBS J 2009;276:2917-25.

Bettendorff L, Wins P, Lesourd M. Subcellular localization and compartmentation of 769 thiamine derivatives in rat brain. Biochim Biophys Acta 1994;1222:1-6. 770

Bizot J-C, Herpin A, Pothion S, Pirot S, Trovero F, Ollat H. Chronic treatment with 771 sulbutiamine improves memory in an object recognition task and reduces some 772 amnesic effects of dizocilpine in a spatial delayed-non-match-to-sample task. Prog 773 Neuropsychopharmacol Biol Psychiatry 2005;29:928-35.

Bourin M, Petit-Demouliere B, Dhonnchadha BN, Hascoet M. Animal models of anxiety 775 in mice. Fundam Clin Pharmacol 2007;21:567-74.

Bradford MM. A rapid and sensitive method for the quantitation of microgram 777 quantities of protein utilizing the principle of protein-dye binding. Anal Biochem 778 1976;72:248-54.

Brenner A. The effects of megadoses of selected B complex vitamins on children with 780 hyperkinesis: controlled studies with long-term follow-up. J Learn Disabil 1982;15: 781 258-64.

Casteels M, Sniekers M, Fraccascia P, Mannaerts GP, Van Veldhoven PP. The role of 2- 783 hydroxyacyl-CoA lyase, a thiamin pyrophosphate-dependent enzyme, in the 784 peroxisomal metabolism of 3-methyl-branched fatty acids and 2-hydroxy 785 straight-chain fatty acids. Biochem Soc Trans 2007;35:876-80. 786

Curzon P, Zhang M, Radek RJ, Fox GB. The behavioral assessment of sensorimotor 787 processes in the mouse. Acoustic startle, sensory gating, locomotor activity, 788 rotarod, beam walking; 2009.

Datta S. Cellular and chemical neuroscience of mammalian sleep. Sleep Med 2010;11:431-40. 790

Djoenaidi W, Notermans SL, Dunda G. Beriberi cardiomyopathy. Eur J Clin Nutr 791 1992;46:227-34.

Du Y, Kowluru A, Kern TS. PP2A contributes to endothelial death in high glucose: 793 inhibition by benfotiamine. Am J Physiol Regul Integr Comp Physiol 2010.

Eudy JD, Spiegelstein O, Barber RC, Wlodarczyk BJ, Talbot J, Finnell RH. Identification 795 and characterization of the human and mouse SLC19A3 gene: a novel member of 796 the reduced folate family of micronutrient transporter genes. Mol Genet Metab 797 2000:71:581-90.

Fleming JC, Tartaglini E, Kawatsuji R, Yao D, Fujiwara Y, Bednarski JJ, et al. Male 799 infertility and thiamine-dependent erythroid hypoplasia in mice lacking thiamine 800 transporter Slc19a2. Mol Genet Metab 2003;80:234-41.

Flood DG, Zuvich E, Marino MJ, Gasior M. The effects of d-amphetamine, methylphe- 802 nidate, sydnocarb, and caffeine on prepulse inhibition of the startle reflex in DBA/2 803 mice. Psychopharmacology (Berl) 2010;211:325-36. 804

Frédérich M, Delvaux D, Gigliobianco T, Gangolf M, Dive G, Mazzucchelli G, et al. 805 Thiaminylated adenine nucleotides. FEBS J 2009·276:3256-68.

Fujiwara M. Absorption, excretion and fate of thiamine and its derivatives in human 807 body. In: Shimazono N, Katsura E, editors. Review of Japanese literature on beriberi 808 and thiamine. Kyoto: Vitamin B Research Committee of Japan; 1965. p. 179-213. 809

Gibson GE, Blass JP. Thiamine-dependent processes and treatment strategies in 810 neurodegeneration. Antioxid Redox Signal 2007;9:1605-19.

Gloire G, Legrand-Poels S, Piette J. NF-kappaB activation by reactive oxygen species: 812 fifteen years later. Biochem Pharmacol 2006;72:1493-505. 813

Golub MS, Germann SL, Lloyd KC. Behavioral characteristics of a nervous system- 814 specific erbB4 knock-out mouse. Behav Brain Res 2004:153:159-70. 815

Granon S, Faure P, Changeux JP. Executive and social behaviors under nicotinic receptor 816 regulation. Proc Natl Acad Sci USA 2003;100:9596-601. 817

Grillon C. Models and mechanisms of anxiety: evidence from startle studies. 818 Psychopharmacology (Berl) 2008;199:421-37. 819

Hammes HP, Du X, Edelstein D, Taguchi T, Matsumura T, Ju Q, et al. Benfotiamine blocks 820 three major pathways of hyperglycemic damage and prevents experimental 821 diabetic retinopathy. Nat Med 2003;9:294-9.

Houzen H, Kanno M. Thiamine and its derivatives inhibit delayed rectifier potassium 823 channels of rat cultured cortical neurons. Neuropharmacology 1998:37:313-22. 824

Inouye K, Katsura E. Clinical signs and metabolism of beriberi patients. In: Shimazono N, 825 Katsura E, editors. Review of Japanese literature on beriberi and thiamine. Kyoto: 826 Vitamin B Research Committee of Japan; 1965. p. 29-63.

Itokawa Y. Thiamine and nervous system function: an historical sketch. Metab Brain Dis 828 1996;11:1-7.

Johnson KR, Longo-Guess C, Gagnon LH, Yu H, Zheng QY. A locus on distal chromosome 830 11 (ahl8) and its interaction with Cdh23 ahl underlie the early onset, age-related 831 hearing loss of DBA/2J mice. Genomics 2008;92:219-25. 
Jones DN. Detoxification and protective functions of nutrients. In: Stipanuk MH, editor Biochemical and physiologica aspects of human nutrtiion. Philadelphia: W.B Saunders Company; 2000. p. 901-16.

Karachalias N, Babaei-Jadidi R, Rabbani N, Thornalley PJ. Increased protein damage in renal glomeruli, retina, nerve, plasma and urine and its prevention by thiamine and benfotiamine therapy in a rat model of diabetes. Diabetologia 2010;53:1506-16.

Kwik-Uribe CL, Golub MS, Keen CL. Chronic marginal iron intakes during early development in mice alter brain iron concentrations and behavior despite postnatal iron supplementation. J Nutr 2000;130:2040-8.

Lazareno S, Dolezal V, Popham A, Birdsall NJ. Thiochrome enhances acetylcholine affinity at muscarinic M4 receptors: receptor subtype selectivity via cooperativity rather than affinity. Mol Pharmacol 2004;65:257-66.

Lonsdale D. A nutritionist's guide to the clinical use of vitamin B-1. Editoin Edition. Tacoma: Life Sciences Press; 1987a.

Lonsdale D. Dysautonomia, a heuristic approach to a revised model for etiology of disease. Evid Based Complement Altern Med 2009;6:3-10.

Lonsdale D. Effect of thiamine tetrahydrofurfuryl disulfide on audiogenic seizures in DBA/2J mice. Dev Pharmacol Ther 1982a;4:28-36.

Lonsdale D. Functional dysautonomia and nutrition. J Am Coll Nutr 1982b;1. 125-125. onsdale D. Hypothesis and case reports: possible thiamin deficiency. J Am Coll Nut 1990;9:13-7.

Lonsdale D. Review of the biochemistry, metabolism and clinical benefits of thiamin(e) and its derivatives. Evid Based Complement Altern Med 2006;3:49-59.

onsdale D. Sudden infant death syndrome requires genetic predisposition, some form of stress and marginal malnutrition. Med Hypotheses 2001:57:382-6.

Lonsdale D. The effect of thiamine tetrahydrofurfuryl disulfide (TTFD) on bloodpressure in spontaneously hypertensive rats (SHR). J Am Coll Nutr 1987b;6. 79-79. Lonsdale D. Thiamine tetrahydrofurfuryl disulfide: a little known therapeutic agent Med Sci Monit 2004;10:RA199-203.

Lonsdale D, Nodar RH, Orlowski JP. Brainstem dysfunction in infants responsive to thiamine disulfide: preliminary studies in four patients. Clin Electroencephalogr 1982;13:82-8

Lonsdale D, Shamberger RJ, Audhya T. Treatment of autism spectrum children with thiamine tetrahydrofurfuryl disulfide: a pilot study. Neuro Endocrinol Lett 2002;23:303-8.

Loo H, Poirier MF, Ollat H, Elatki S. Effects of sulbutiamine (Arcalion 200) on psychobehavioral inhibition in major depressive episodes. Encéphale 2000;26:70-5.

Marini NJ, Gin J, Ziegle J, Keho KH, Ginzinger D, Gilbert DA, et al. The prevalence of folate-remedial MTHFR enzyme variants in humans. Proc Natl Acad Sci USA 2008;105:8055-60.

Matsui K, Nakahara H, Watanabe H, Tamatsu H, Nakazawa M, Nakagawa Y, et al. Inhibition by thiamine tetrahydrofurfuryl disulfide (TTFD) of the arachidonic acid cascade-line activation as evidenced in the heart-lung preparation of the dog. Jpn J Pharmacol 1985;39:375-9.

McCaughran Jr J, Bell J, Hitzemann R. On the relationships of high-frequency hearing loss and cochlear pathology to the acoustic startle response (ASR) and prepulse inhibition of the ASR in the BXD recombinant inbred series. Behav Genet 1999;29:21-30.

McCaughran Jr J, Mahjubi E, Decena E, Hitzemann R. Genetics, haloperidol-induced catalepsy and haloperidol-induced changes in acoustic startle and prepulse inhibition. Psychopharmacology (Berl) 1997;134:131-9.

McCaughran Jr JA, Bell 111 J, Hitzemann RJ. Fear-potentiated startle response in mice: genetic analysis of the C57BL/6J and DBA/2J intercross. Pharmacol Biochem Behav 2000;65:301-12.

McCormick DB. Niacin, riboflavin, and thiamin. In: Stipanuk, editor. Philadelphia: W.B. Saunders Company; 2000. p. 458-82.

McGrane MM. Carbohydrate metabolism-synthesis and oxidation. In: Stipanuk MH, editor. Biochemical and physiological aspects of human nutrition. Phladelphia: W.B Saunders Company; 2000. p. 158-210.

Meador KJ, Nichols ME, Franke P, Durkin MW, Oberzan RL, Moore EE, et al, Loring DW. Evidence for a central cholinergic effect of high-dose thiamine. Ann Neurol 1993;34:724-6.

Micheau J, Durkin TP, Destrade C, Rolland Y, Jaffard R. Chronic administration of sulbutiamine improves long term memory formation in mice: possible cholinergic mediation. Pharmacol Biochem Behav 1985;23:195-8.

Mimori Y, Katsuoka H, Nakamura S. Thiamine therapy in Alzheimer's disease. Metab Brain Dis 1996;11:89-94.

Mitoma C. Metabolic disposition of thiamine tetrahydrofurfuryl disulfide in dog and man. Drug Metab Dispos: Biol Fate Chem 1973;1:698-703.

Mizutani M, Ihara T, Kanamori H, Takatani O, Kajiwara K. Effect of thiamine tetrahydrofurfuryl disulfide upon developing fetuses of mice and rats. J Takeda Res Lab 1971;30:131-7.

Mizutani M, Ihara T, Kaziwara K. Effects of orally administered thiamine tetrahydrofurfuryl disulfide on foetal development of rabbits and monkeys. Jpn J Pharmacol 1972;22: $115-24$.

Moy SS, Nadler JJ, Young NB, Perez A, Holloway LP, Barbaro RP, et al. Mouse behavioral tasks relevant to autism: phenotypes of 10 inbred strains. Behav Brain Res 2007; $176: 4-20$

Nakagawasai O, Tadano T, Hozumi S, Taniguchi R, Yamadera F, Tan-No K, et al Involvement of muscarinic receptor on the impairment of avoidance learning in mice fed a thiamine-deficient diet. Biog Amines 2001;16:199-210.

Nakagawasai O, Tadano T, Niijima F, Tan-No K, Kisara K. Immunohistochemical estimation of rat brain somatostatin on avoidance learning impairment induced by thiamine deficiency. Brain Res Bull 2000;51:47-55.

Nakagawasai O, Yamadera F, Iwasaki K, Asao T, Tan-No K, Niijima F, et al. Preventive effect of kami-untan-to on performance in the forced swimming test in thiamine- deficient mice: relationship to functions of catecholaminergic neurons. Behav Brain 917 Res 2007;177:315-21.

Nakagawasai O, Yamaderea F, Iwasaki K, Arai H, Taniguchi R, Tan-no K, et al. Effect of 919 Kami-Untan-To on the impairment of learning and memory induced by thiamine- 920 deficient feeding in mice. Neuroscience 2004;125:233-41. 921

Nozaki S, Mizuma H, Tanaka M, Jin G, Tahara T, Mizuno K, et al. Thiamine 922 tetrahydrofurfuryl disulfide improves energy metabolism and physical perfor- 923 mance during physical-fatigue loading in rats. Nutr Res 2009;29:867-72. 924

N.R.C.U.S.S.o.L.A. Nutrition, Nutrient requirements of laboratory animals, Editoin 925 Edition. Washington, D.C: National Academy of Sciences; 1995.

Oi Y, Shishido C, Wada K, Odaka H, Ikeda H, Iwai K. Allylthiamindisulfide and related 927 compounds enhance thermogenesis with increasing noradrenaline and adrenaline 928 secretion in rats. J Nutr Sci Vitaminol (Tokyo) 1999;45:643-53.

ivier B, Leahy C, Mullen T, Paylor R, Groppi VE, Sarnyai Z, et al. The DBA/2J strain and 930 prepulse inhibition of startle: a model system to test antipsychotics? Psychophar- 931 macology (Berl) 2001;156:284-90.

Pan X, Gong N, Zhao J, Yu Z, Gu F, Chen J, et al. Powerful beneficial effects of 933 benfotiamine on cognitive impairment and beta-amyloid deposition in amyloid 934 precursor protein/presenilin-1 transgenic mice. Brain 2010;133:1342-51. 935

Panksepp JB, Lahvis GP. Social reward among juvenile mice. Genes Brain Behav 2007;6: 936 661-71.

. startle response. Psychopharmacology (Berl) 1997;132:169-80.

Pekovich SR, Martin PR, Singleton CK. Thiamine deficiency decreases steady-state 940 transketolase and pyruvate dehydrogenase but not alpha-ketoglutarate dehydro- 941 genase mRNA levels in three human cell types. J Nutr 1998a;128:683-7. 942

Pekovich SR, Poggi V, Martin PR, Singleton CK. Sensitivity to thiamine deficiency in 943 cultured human cells is dependent on cell type and is enhanced in cells from thiamine- 944 responsive megaloblastic anemia patients. J Nutr Biochem 1998b;9:215-22. 945

Peskin MR, Newton G, Brin M. Thiamine deficiency, infantile manipulation and startle 946 response in rats. J Nutr 1967;91:20-4.

Reddy SY, Pullakhandam R, Dinesh Kumar B. Thiamine reduces tissue lead levels in rats: 948 mechanism of interaction. Biometals 2010:23:247-53.

Rosenwasser AM. Functional neuroanatomy of sleep and circadian rhythms. Brain Res 950 Rev 2009;61:281-306.

Salminen A, Kaarniranta K. Glycolysis links p53 function with NF-kappaB signaling: 952 impact on cancer and aging process. J Cell Physiol 2010;224:1-6.

Semenova S, Bespalov A, Markou A. Decreased prepulse inhibition during nicotine 954 withdrawal in DBA/2J mice is reversed by nicotine self-administration. Eur J 955 Pharmacol 2003;472:99-110.

Shah SN. Adjuvant role of vitamin B analogue (sulbutiamine) with anti-infective 957 treatment in infection associated asthenia. J Assoc Physicians India 2003;51:891-5. 958

Sheline CT, Wei L. Free radical-mediated neurotoxicity may be caused by inhibition of 959 mitochondrial dehydrogenases in vitro and in vivo. Neuroscience 2006;140:235-46. 960 Review of Japanese literature on beriberi and thiamine, Editoin Edition. In: Shimazono N, 961 Katsura E, editors. Kyoto: Vitamin B Research Committee of Japan; 1965.

Spiegel R, Shag A, Edvardson S, Mandel $H$, Stepensky P, Shalev SA, Horovit SLC25A19 mutation as a cause of neuropathy and bilateral striatal necrosis. Ann 964 Neurol 2009;66:419-24.

Stevens KE, Adams CE, Yonchek J, Hickel C, Danielson J, Kisley MA. Permanent 966 improvement in deficient sensory inhibition in DBA/2 mice with increased 967 perinatal choline. Psychopharmacology (Berl) 2008;198:413-20. thiamine tetrahydro-furfuryl disulfide to 4-methylthiazole-5-acetic acid in conven- 970 tional and germfree rats under various dosing conditions. J Nutr 1968;96:433-44. 971

Swerdlow NR, Weber M, Qu Y, Light GA, Braff DL. Realistic expectations of prepulse 972 inhibition in translational models for schizophrenia research. Psychopharmacology 973 2008;199:331-88.

Tallaksen CME, Tauboll E. Excitatory effect of thiamin on CA1 pyramidal neurones in rat 975 hippocampal slices in vitro. Eur J Neurol 2000;7:693-8.

Terranova ML, Laviola G. delta-Opioid modulation of social interactions in juvenile mice 977 weaned at different ages. Physiol Behav 2001;73:393-400.

Thomson AD, Marshall EJ. The natural history and pathophysiology of Wernicke's 979 encephalopathy and Korsakoff's psychosis. Alcohol Alcohol 2006;41:151-8. 980

Toliver-Kinsky T, Wood T, Perez-Polo JR. Nuclear factor kappaB/p49 is a negative 981 regulatory factor in nerve growth factor-induced choline acetyltransferase 982 promoter activity in PC12 cells. J Neurochem 2000;75:2241-51.

Turner J Hughes LF, Toth LA. Sleep, activity, temperature and arousal responses of mice deficient for muscarinic receptor M2 or M4. Life Sci 2010;86:158-69.

Van Reeth O. Pharmacologic and therapeutic features of sulbutiamine. Drugs Today 986 (Barc) 1999;35:187-92.

Verma S, Reddy K, Balakumar P. The defensive effect of benfotiamine in sodium 988 arsenite-induced experimental vascular endothelial dysfunction. Biol Trace Elem 989 Res 2010;137:96-109.

Wilkinson TJ, Hanger HC, Elmslie J, George PM, Sainsbury R. The response to treatment 991 of subclinical thiamine deficiency in the elderly. Am J Clin Nutr 1997:66:925-8. 992

Woelk H, Lehrl S, Bitsch R, Kopcke W. Benfotiamine in treatment of alcoholic 993 polyneuropathy: an 8-week randomized controlled study (BAP I Study). Alcohol 994 Alcohol 1998;33:631-8.

Yadav UC, Kalariya NM, Srivastava SK, Ramana KV. Protective role of benfotiamine, a 996 fat-soluble vitamin B1 analogue in lipopolysaccharide-induced cytotoxic signals in 997 murine macrophages. Free Radic Biol Med 2010;48:1423-34. 998

Yamashita H, Zhang YX, Nakamura S. The effects of thiamin and its phosphate esters on 999 dopamine release in the rat striatum. Neurosci Lett 1993;158:229-31. 